\title{
APLICAÇÕES DE TRÍTIO NA DETERMINAÇÃO DE TEMPOS DE RESIDÊNCIA NO CICLO HIDROLÓGICO
}

\author{
Aurélio Fernando Paiva SILVA \\ Stela Dalva Santos COTA \\ Rubens Martins MOREIRA
}

\section{RESUMO}

Como traçador em hidrologia, o trítio pode ser utilizado para inúmeras e variadas finalidades, tais como na datação de águas subterrâneas, em medidas hidráulicas, na determinação da distribuição de tempos de residência em grandes corpos de água e na atmosfera, em medições de balanço hídrico e em estudos da dispersão de contaminantes. Séries temporais de teor de trítio na precipitação e em pontos de observação específicos do sistema hidrológico são utilizadas para se obter modelos de parâmetros agrupados, capazes de descrever a distribuição de tempos de residência da água nos compartimentos do ciclo hidrológico. Este artigo apresenta uma descrição dos aspectos teóricos e práticos necessários para a aplicação dessas técnicas, o estado da arte de estudos científicos envolvendo a aplicação de trítio ambiental em águas subterrâneas e em bacias hidrológicas, bem como as novas tendências em desenvolvimento na área.

Palavras-chave: Traçador ambiental; Trítio; Tempos de residência; Hidrologia.

\section{ABSTRACT}

\section{APPLICATIONS OF TRITIUM IN THE DETERMINATION OF RESIDENCE} TIMES IN THE HYDROLOGICAL CYCLE. As a tracer in hydrology, tritium can be used for different purposes, such as groundwater dating; hydraulic measurements; determination of the distribution of residence times in large bodies of water and in the atmosphere; water balance measurements, and in studies on the dispersion of contaminants. Time series of tritium concentration in rain water and at specific observation points of the hydrological system are used to obtain lumped-parameter models capable of describing the distribution of residence times of the water in the hydrological cycle compartments. This paper presents a description of theoretical and practical aspects involved in the application of these techniques, the state-of-the-art of scientific studies involving the application of environmental tritium in groundwater and watersheds, as well as the new on-going trends in this area.

Keywords: Environmental tracer; Tritium; Residence time; Hydrology.

\section{INTRODUÇÃO}

Os núcleos de átomos do elemento hidrogênio podem ser de três espécies naturais, ou nuclídeos: o hidrogênio comum ou ${ }^{1} \mathrm{H}$ ou prótium (1 próton, 1 nêutron, abundância: 99,9885\%), o deutério ou ${ }^{2} \mathrm{H}$ ou $\mathrm{D}$ (1 próton, 2 nêutrons, abundância: $0,000115 \%$ ) e o trítio ${ }^{3} \mathrm{H}$ ou $\mathrm{T}$ (1 próton, 3 nêu- trons). Os dois primeiros são estáveis, mas o trítio é radioativo; por isso sua abundância não é fixa. O decaimento radioativo do trítio se dá pela emissão de uma partícula beta $\left(\beta^{-}\right)$e um antineutrino $(\bar{v})$, liberando uma energia de $18,6 \mathrm{keV}$ (ou $2,98 \times 10^{-15} \mathrm{~J}$ ) e gerando o ${ }^{3} \mathrm{He}$, um isótopo estável do hélio (MOOK 2000):

$$
{ }_{1}^{3} \mathrm{H} \rightarrow{ }_{2}^{3} \mathrm{He}+\beta^{-}+\bar{v}
$$


O trítio só veio a ser descoberto em 1934 por Rutherford em colaboração com Mark Oliphant e Paul Hartek. Eles bombardearam o deutério - que havia sido descoberto apenas três anos antes por Harold Urey - com dêuterons, que são os núcleos do próprio deutério. Provavelmente desencadearam uma reação de fusão nuclear: ${ }^{2} \mathrm{H}+{ }^{2} \mathrm{H} \rightarrow{ }^{3} \mathrm{H}$ ${ }^{1} \mathrm{H}$. No entanto, Rutherford não conseguiu isolar o trítio e os grandes méritos couberam a Luis Alvarez, que, em 1938, foi quem constatou que o trítio é radioativo e ainda mediu a sua meia-vida. Cerca de uma década depois e com a atmosfera mais enriquecida em trítio, Willard Libby desenvolveu aplicação deste radionuclídeo na datação de águas (UNIVERSITY OF WATERLOO 2021).

Devido às suas propriedades, o trítio é um dos principais traçadores radioativos utilizados no mundo. Em primeiro lugar porque é um traçador quase-ideal da água, tanto para identificar e quantificar seus movimentos, como para medir a sua idade. Mas também porque é um traçador já disponível no meio-ambiente e por ser um dos radionuclídeos menos agressivos.

$\mathrm{O}$ decaimento radioativo se dá segundo uma lei exponencial, de maneira que a atividade do trítio decai pela metade a cada 12,3 anos, a chamada meia-vida de um radionuclídeo. Porém, o trítio não desaparece no universo, assim como muitos outros radionuclídeos naturais, pois está continuamente sendo gerado por outras reações nucleares naturais (CLARK \& FRITZ 1997) e algumas não naturais.

As duas principais fontes de radionuclídeos com meia-vidas consideradas curtas numa escala geológica podem ser classificadas como cosmogênicas ou antropogênicas (MASARIK 2010). Nas fontes cosmogênicas, os radionuclídeos são gerados por interações com os raios cósmicos. As fontes antropogênicas compreendem reações ativadas pela atividade humana como os artefatos bélicos, reatores nucleares e plantas de reprocessamento de seus combustíveis. A radioatividade gerada pelas fontes antropogênicas é muito pequena comparada com a radioatividade ambiental, mas geralmente é muito mais concentrada.

Como uma primeira demonstração de sua utilidade enquanto traçador, o trítio apresenta a versatilidade de ser gerado por ambas estas fontes. A geração cosmogênica ocorre quando partículas de origem cosmogênica ou secundárias, principalmente nêutrons e prótons com velocidades próximas à velocidade da luz, interagem com o nitrogênio ou oxigênio na atmosfera. Diversas reações nucleares são possíveis nessas condições. Quando, após vários choques, os nêutrons perdem parte de sua energia inicial, mas suas velocidades ainda são superiores a $14.000 \mathrm{~km} / \mathrm{s}$, a reação com maior probabilidade de ocorrência é:

$$
{ }_{7}^{14} \mathrm{~N}+{ }^{1} n \rightarrow{ }_{6}^{12} \mathrm{C}+{ }_{1}^{3} \mathrm{H}
$$

Do balanço entre o trítio produzido desta forma e sua perda por decaimento radioativo, tem-se um estoque estacionário entre 3 e $10 \mathrm{~kg}$ do radionuclídeo na Terra. Deste total, 93\% está alojado na hidrosfera e apenas $7 \%$ cabem à atmosfera (FERRONSKY \& POLYAKOV 2012).

Dada esta massa irrisória, as quantidades medidas de trítio são dadas numa unidade mais prática, a UT (unidade de trítio). Assim, 1 UT = 1 átomo de ${ }^{3} \mathrm{H}$ por $10^{18}$ átomos de ${ }^{1} \mathrm{H}$, que correspondem a uma concentração de radioatividade igual a 0,119 $\mathrm{Bq} / \mathrm{L}$ (sendo $1 \mathrm{~Bq}=1$ desintegração/s).

Além desta inesgotável fonte, o trítio também pode ser gerado pelas fontes antropogênicas, que são designadas por alguns autores como "tecnogênicas". Nos reatores nucleares, um imenso fluxo de nêutrons copiosamente produzidos pela fissão do urânio, em diversos níveis do espectro de energias, propicia uma variedade de reações nucleares com os elementos da molécula de água, entre as quais:

$$
{ }_{1}^{2} \mathrm{H}+{ }^{1} n \rightarrow{ }_{1}^{3} \mathrm{H}+\gamma
$$

Uma importante reação para a produção de trítio tecnogênico é obtida pelo bombardeio de alvo de lítio com nêutrons:

$$
{ }_{3}^{6} \mathrm{Li}+{ }^{1} n \rightarrow{ }_{2}^{4} \mathrm{He}+{ }_{1}^{3} \mathrm{H}
$$

É essa reação que permite a obtenção de trítio em altas concentrações $\left(10^{11} \mathrm{~Bq} / \mathrm{mL}\right)$, que pode ser usado como traçador artificial em estudos ambientais como hidrologia e dispersão atmosférica ou no setor produtivo como tempos de residência em grandes sistemas, recuperação de petróleo em reservatórios, etc. (LOWENTHAL \& AIREY 2001, IAEA 2012).

Mas também foi essa fonte de geração de trítio a responsável pelas elevadas descargas do radionuclídeo na atmosfera no final dos anos 50 e início dos anos 60 do século passado. Isso porque o poder de um artefato nuclear pode ser impulsionado (boosted-fission nuclear weapons) pela adição de lítio e deutério. Ao ser bombardeado pelos nêutrons provenientes da fissão, o lítio produz trítio que detona a energética reação de fusão com o deutério ( $\mathrm{D}+\mathrm{T} \rightarrow \mathrm{He}+n+14,1 \mathrm{MeV})$ e reforça consideravelmente o rendimento do urânio. $\mathrm{O}$ pico de 
testes nucleares na atmosfera naquela época elevou em 1000 vezes a concentração de trítio na atmosfera do hemisfério norte do planeta (Figura 1). Essa injeção de trítio na atmosfera possibilitou a utilização do radionuclídeo para a datação das águas subterrâneas jovens (CLARK \& FRITZ 1997, MOOK 2000).

Como a grande maioria dos testes nucleares teve lugar no hemisfério norte, ao ser transportado pelos ventos para o hemisfério sul, as concentrações de trítio na atmosfera se diluem bastante e, como indica a figura 1 , o valor máximo para o hemisfério sul foi mais de 50 vezes inferior (CLARK
\& FRITZ 1997, MOOK 2000) Além disso, o sistema de circulação dos ventos na atmosfera retardou o transporte dos radionuclídeos para o hemisfério sul, de forma que o pico de radioatividade neste hemisfério se deu com um atraso de 1 a 2 anos em relação ao do hemisfério norte. As formas dos picos também diferiram, no norte o pico foi mais agudo e no sul mais disperso; todas essas características podem ser apreciadas na figura 1. Passadas 5 meias-vidas do ${ }^{3} \mathrm{H}$ após a injeção do pico, as concentrações atuais diminuíram dramaticamente e no hemisfério sul já pouco se diferenciam dos níveis pré-testes nucleares, o que exige métodos analíti-
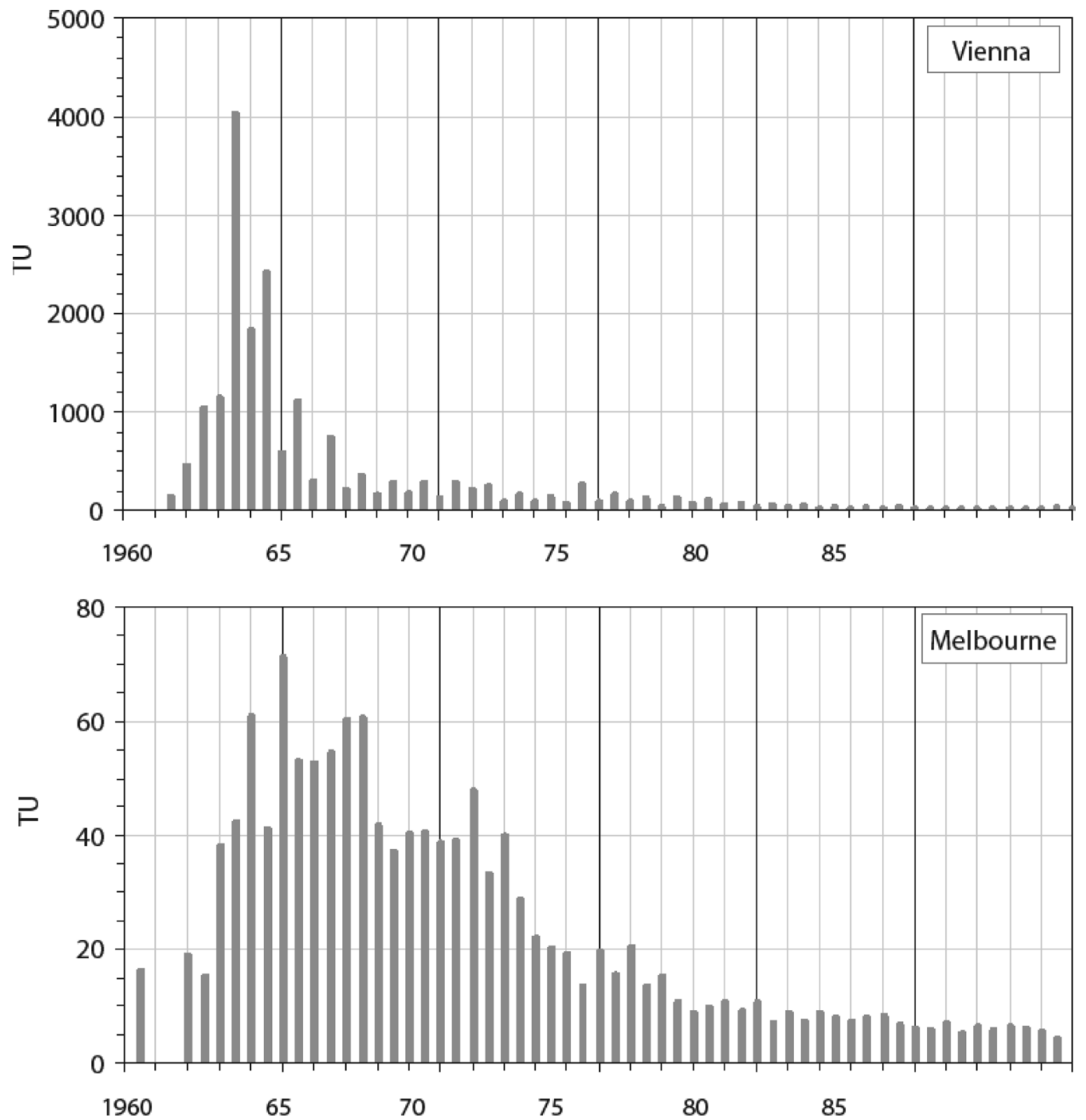

FIGURA 1 - Variação da atividade de trítio na atmosfera do hemisfério norte e do hemisfério sul. Fonte: GAT et al. (2001). 
cos ultrassensíveis para a determinação das concentrações de trítio em águas.

Diferentemente da geração tecnogênica, a geração cosmogênica ocorre na alta atmosfe$\mathrm{ra}$, entre 10 e $40 \mathrm{~km}$ acima da superfície da Terra. Imediatamente após sua geração, o trítio é oxidado e incorporado em moléculas de água HTO (contendo um átomo de trítio, T) que, eventualmente, se prendem em aerossóis e posteriormente se nucleiam em gotículas para formar as precipitações. Após gastar entre 1 a 2 meses neste percurso descendente o radionuclídeo é assim introduzido no ciclo hidrológico tal como esquematizado na figura 2. É óbvio que esta espécie de moléculas de água, chamada água tritiada, constitui um traçador praticamente perfeito ao acompanhar as peripécias pelas quais passam as massas de água no curso do ciclo hidrológico (CLARK \& FRITZ 1997, MOOK 2000).

O traçador é um material (ou energia) que se comporta o mais semelhante possível ao sistema estudado, mas que tenha alguma propriedade especial que o distinga e que seja detectável a muito baixas concentrações. Ora, essas três condições são praticamente incompatíveis entre si e, via de regra, um comportamento específico ao traçador sempre pode introduzir um quantum de incorreção nas informações que fornecem, sejam sobre reações químicas ou processos biológicos, mudanças de fase ou o simples deslocamento mecânico. Porém, a molécula da água tritiada emite um sinal, a radiação beta, detectável com precisão por equipamentos sofisticados, embora seja de baixíssima energia e que, portanto, não interfere na grande maioria dos fenômenos hidrológicos. Contudo, não é com as radiações beta emitidas pelo trítio que deve-se atentar. A questão crucial é que o trítio é três vezes mais pesado do que o hidrogênio. Pode-se pensar que em termos de unidades de massa atômica (u) a massa de uma molécula de água comum HHO é 18 u e a de água tritiada HTO é 20 u. Ou seja, a insignificante diferença de $5 \times 10^{-24} \mathrm{~g}$. A situação não mudaria mesmo no caso de uma molécula de TTO (cuja abundância na natureza é totalmente desprezível).

Porém, em se tratando de fenômenos que ocorrem em um nível atômico, essas diferenças são significativas. Dados comparativos entre água comum e de água pesada (DDO e TTO, sendo que D refere-se a deutério e $\mathrm{T}$, ao trítio) indicam tais diferenças em várias propriedades: entalpia de evaporação, pressão de vapor, pontos de fusão e de ebu-

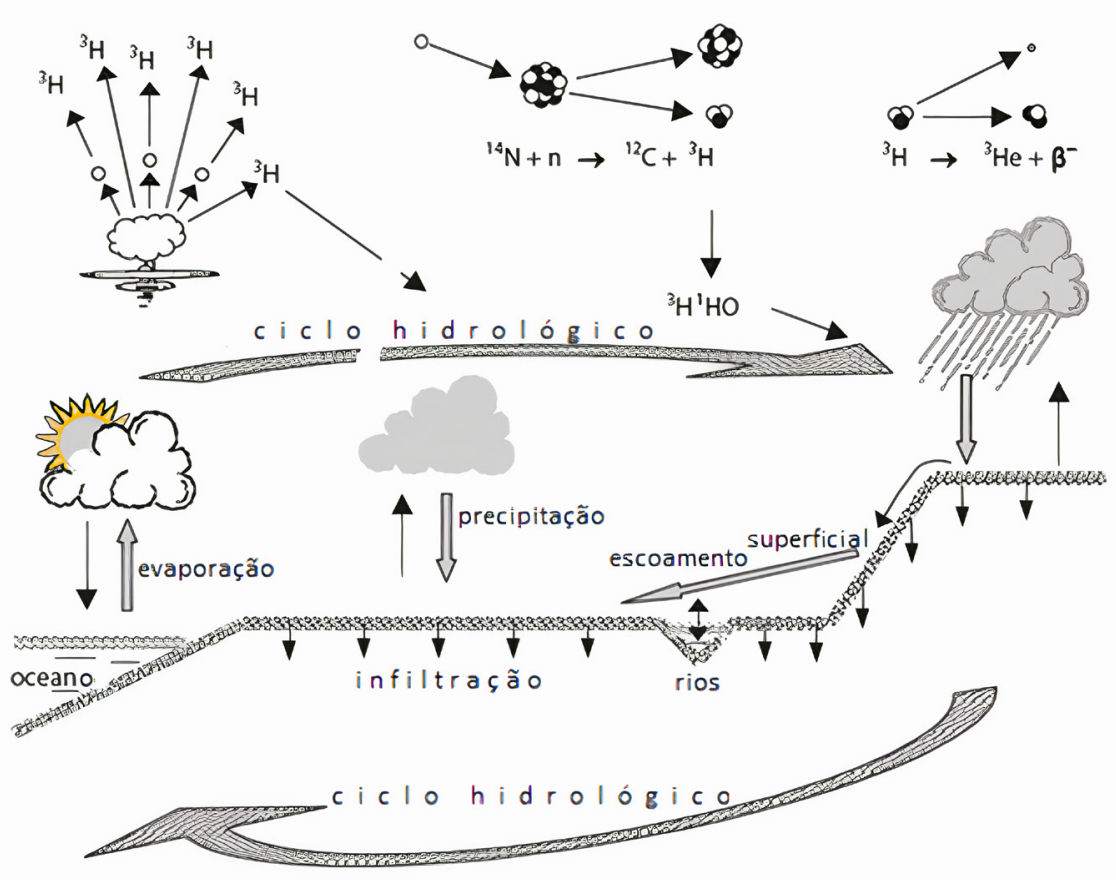

FIGURA 2 - Origem e trajetória do trítio no ciclo hidrológico. Fonte: Adaptado de GEYH (2000). 
lição, temperatura crítica, densidade, viscosidade e calor latente de fusão (CRISS 1999). Não é de se espantar que todas essas diferenças sejam refletidas na toxicidade das águas pesadas, até mesmo na deuterada que não é radioativa. Isso indica que as diferenças nas massas dos isótopos têm uma leve influência em suas propriedades químicas e físicas, e que essas diferenças são tanto mais apreciáveis quanto mais leves forem os nuclídeos (KENDALL \& CALDWELL 1998, WHITE 2015). Esse efeito é atribuído às interações entre as moléculas, na fase gasosa e, principalmente, na líquida. As propriedades de transporte de massa e momentum são das mais acometidas por estarem ligadas às forças intermoleculares, em especial as ligações de hidrogênio (GAT 2010). Desta forma as moléculas isotópicas com diferentes massas não se comportam da mesma forma em processos como mudanças de fase ou reações químicas; geralmente as moléculas mais leves evaporam, reagem, etc. mais rapidamente do que as mais pesadas. Resulta que as composições isotópicas (também chamadas de assinaturas isotópicas) de uma dada água sofrendo evaporação serão diferentes no vapor e no líquido remanescente. Esse fenômeno é referido como fracionamento isotópico (ALBARÈDE 2009).

Suponhamos uma molécula de água tritiada em um processo de transição de uma fase $A$ para uma fase $B$. Haverá um fracionamento e, portanto, as assinaturas do trítio nas duas fases serão diferentes (KUMAR et al. 2016). A razão isotópica do trítio em uma determinada fase será expressa como:

$$
R=\frac{\left[{ }^{3} \mathrm{H}\right]}{\left[{ }^{1} \mathrm{H}\right]}
$$

onde os valores entre colchetes correspondem ao número de átomos (ou à concentração) de trítio e hidrogênio nesta fase. A magnitude do fracionamento na mudança de fase pode então ser expressa por um fator de fracionamento $\alpha$ que é a razão entre as razões isotópicas do trítio nas duas fases:

$$
\alpha_{A \rightarrow B}=\frac{R_{A}}{R_{B}}=\frac{\left(\left[{ }^{3} H\right] /\left[{ }^{1} H\right]\right)_{A}}{\left(\left[{ }^{3} H\right] /\left[{ }^{1} H\right]\right)_{B}}
$$

Já nos primórdios dos estudos da isotopia, Urey havia se debruçado sobre o fenômeno e desenvolvido as bases teóricas para a compreensão do fracionamento dependente da massa (UREY 1947). Ele e outros pesquisadores mostraram, com base nos princípios da termodinâmica, da mecânica estatística e da mecânica quântica, que os fatores de fracionamento podem ser previstos pelo menos para as espécies moleculares mais simples, desde que o processo tenha ocorrido em condições de equilíbrio termodinâmico (KENDALL \& CALDWELL 1998, SHARP 2007, WHITE 2015). Essas situações são pouco comuns ao longo do ciclo hidrológico, mas uma exceção é a precipitação, onde a condensação se desenvolve num íntimo contato entre o vapor e as gotículas de água no interior das nuvens a $100 \%$ de umidade. Já no processo inverso, a formação das grandes massas de vapor ocorre a baixas umidades e sob a ação dos ventos e da rápida mistura com outros vapores. $\mathrm{Ou}$ seja, trata-se de um processo regido pela advecção e difusão, essencialmente em não-equilíbrio, e por essas razões o fracionamento resultante é chamado de cinético, embora seja uma designação inapropriada, sendo preferível usar o termo fracionamento por transporte (GAT 2010). Em cenários de não-equilíbrio o fracionamento pode ser abordado por outros modelos (CRISS 1999, FAURE \& MESSING 2005, WHITE 2015), todos eles com suas limitações. Os fatores de fracionamento também podem ser medidos em laboratório e observa-se que são altamente dependentes da temperatura por meio de uma relação inversa:

$$
\ln \alpha_{A \rightarrow B}=\frac{C_{1}}{T^{2}}+\frac{C_{2}}{T}+C_{3}
$$

onde $T$ é a temperatura e os valores são ajustados aos resultados experimentais.

Obviamente, no caso do radionuclídeo ${ }^{3} \mathrm{H}$ a previsão do fator de fracionamento é mais complexa porque as concentrações variam no tempo e dependem de metodologias especiais para as medições (KUMAR et al. 2016). Mas, por analogia com o fracionamento do deutério, sabe-se perfeitamente que uma ligação H-H é muito mais facilmente rompida do que $\mathrm{H}-\mathrm{T}$ e esse efeito isotópico resulta num ínfimo atraso da água tritiada em relação à água comum nos diversos processos ilustrados na figura 2. Uma evidência da estratificação do trítio é a distribuição espacial desse radionuclídeo nas precipitações, onde se pode notar o efeito de continuidade, isto é, a progressiva diminuição da concentração do isótopo em precipitações mais afastadas da costa, oriundas de nuvens progressivamente deletadas nos nuclídeos mais pesados.

Resumindo, nem o trítio é um traçador absolutamente ideal e nem sempre as teorias do fracionamento podem ser rigorosamente aplicadas, mas seguindo cuidadosamente os protocolos de aplicação e detecção deste radionuclídeo é de se esperar que os desvios acima discutidos sejam inferiores 
às incertezas experimentais características dos trabalhos no meio ambiente. De qualquer forma, os efeitos isotópicos são totalmente irrelevantes na escala da maioria das medições praticadas em hidrologia. Já para os isótopos estáveis, são justamente os efeitos do fracionamento que irão fornecer preciosas informações sobre as fontes ou os processos que os causaram. E no que diz respeito à metodologia de datação das águas o efeito isotópico em nada influi, pois o decaimento radioativo é um outro processo, que ocorre apenas no núcleo do radionuclídeo, que em nada é afetado pelo ambiente exterior a este núcleo e muito menos a outros nuclídeos em suas imediações.

Como traçador em hidrologia, o trítio pode ser utilizado para inúmeras e variadas finalidades (MAZOR 2003). Sem esgotar todo este amplo campo de aplicações é possível citar:

- datação de águas subterrâneas,

- medidas hidráulicas de várias espécies (vazão volumétrica em rios, canais e tubulações de grande porte),

- dispersão de efluentes e distribuição de tempos de residência em grandes corpos de água e na atmosfera,

- medidas de fluxo de água em meios porosos (aquíferos ou reservatórios de petróleo) e detecção de interconexões,

- detecção e localização de fugas em barragens e perdas por evaporação,

- localização e delimitação de nuvens de contaminantes no subsolo,

- medições de balanço hídrico,

- calibração de modelos numéricos.

Diversas dessas aplicações requerem a disponibilidade de uma base de dados pretéritos na região de estudo, tanto para o seu planejamento inicial, como para uma proveitosa avaliação das informações obtidas. Porém, a ausência dessas informações é endêmica em regiões afastadas e mesmo em locais mais povoados do Brasil. A Agência Internacional de Energia Atômica - AIEA, um órgão das Nações Unidas para o desenvolvimento e utilização pacífica da energia nuclear com sede em Viena, em cooperação com a Organização Mundial de Meteorologia sediada em Genebra, lançaram em 1960 um projeto de implantação de uma rede monitoramento de isótopos no meio ambiente, cognominada GNIP (Global Network of Isotopes in Precipitation), com o propósito de abranger todos os continentes do globo terrestre. O projeto iniciou justamente com a monitoração do trítio, pela sua abrangência de suas aplicações. Com o passar do tempo as concentrações de trítio na atmosfera diminuíram e os isótopos estáveis ganharam importância e foram incluídos no projeto. De acordo com BEDMAR \& ARAGUÁS (2002), havia mais de 500 estações espalhadas pelo planeta no início desse século. Na figura 3 estão indicadas as localizações das estações de monitoração da GNIP. O Brasil chegou a operar 13 estações, mas todas foram fechadas até a década de 1990 . Novas estações estão entrando em operação, com a retomada em 2008 (COTA et al. 2013, FRANZINI et al. 2019). Os dados monitorados podem ser acessados em https://nucleus.iaea.org/wiser. Recentemente, a AIEA expandiu essa iniciativa de monitoração para as bacias hídricas a partir da rede GNIR (Global Network of Isotopes in Rivers).

Embora a radiação emitida pelo trítio seja relativamente pouco energética, os cuidados exigidos para a manipulação de substâncias radioativas devem ser observados quando se trabalha com água tritiada. O trítio emite uma radiação beta, que é um elétron e que, por portar uma carga elétrica, interage rapidamente com a matéria e assim tem baixo poder de penetração; a barreira da epiderme humana já pode impedir que ela atinja órgãos sensíveis. A energia dissipada no decaimento, de $18,59 \mathrm{keV}$, é a mais fraca das radiações na tabela de radionuclídeos. Um neutrino (massa zero) é emitido simultaneamente com a partícula $\beta$ e os $18,59 \mathrm{keV}$ ficam repartidos entre as duas radiações de uma maneira aleatória. Resulta que as partículas $\beta$ se distribuem em um espectro assimétrico de energias inferiores a 18,59 keV. Em que pese essa aparente ausência de riscos, a água tritiada pode causar malefícios se for ingerida, inalada ou absorvida através da pele. A meia-vida biológica varia entre 1 e 2 semanas, $o$ que reduz o risco de bioacumulação.

O trabalho seguro com água tritiada exige, portanto, os cuidados comuns aos demais radioisótopos: profissionais credenciados responsabilizando-se pelas atividades, licenças e permissões, laboratórios adequados dispondo de medidores de radiação fixos e portáteis, blindagens, ventilação, EPI, etc. Em todas as etapas de um trabalho o princípio ALARA deve ser observado (IAEA 2014). Informações detalhadas sobre estes quesitos podem ser obtida no site www.cnen.gov.br. As normas brasileiras (CNEN 2014) limitam a dose efetiva anual de corpo inteiro para indivíduos do público a $1 \mathrm{mSv}$ e estabelecem níveis de isenção aos seus próprios requisitos, ou seja: quantidades de atividade abaixo de um nível fixado pela própria CNEN. Para o ${ }^{3} \mathrm{H}$, os níveis de isenção são 6 


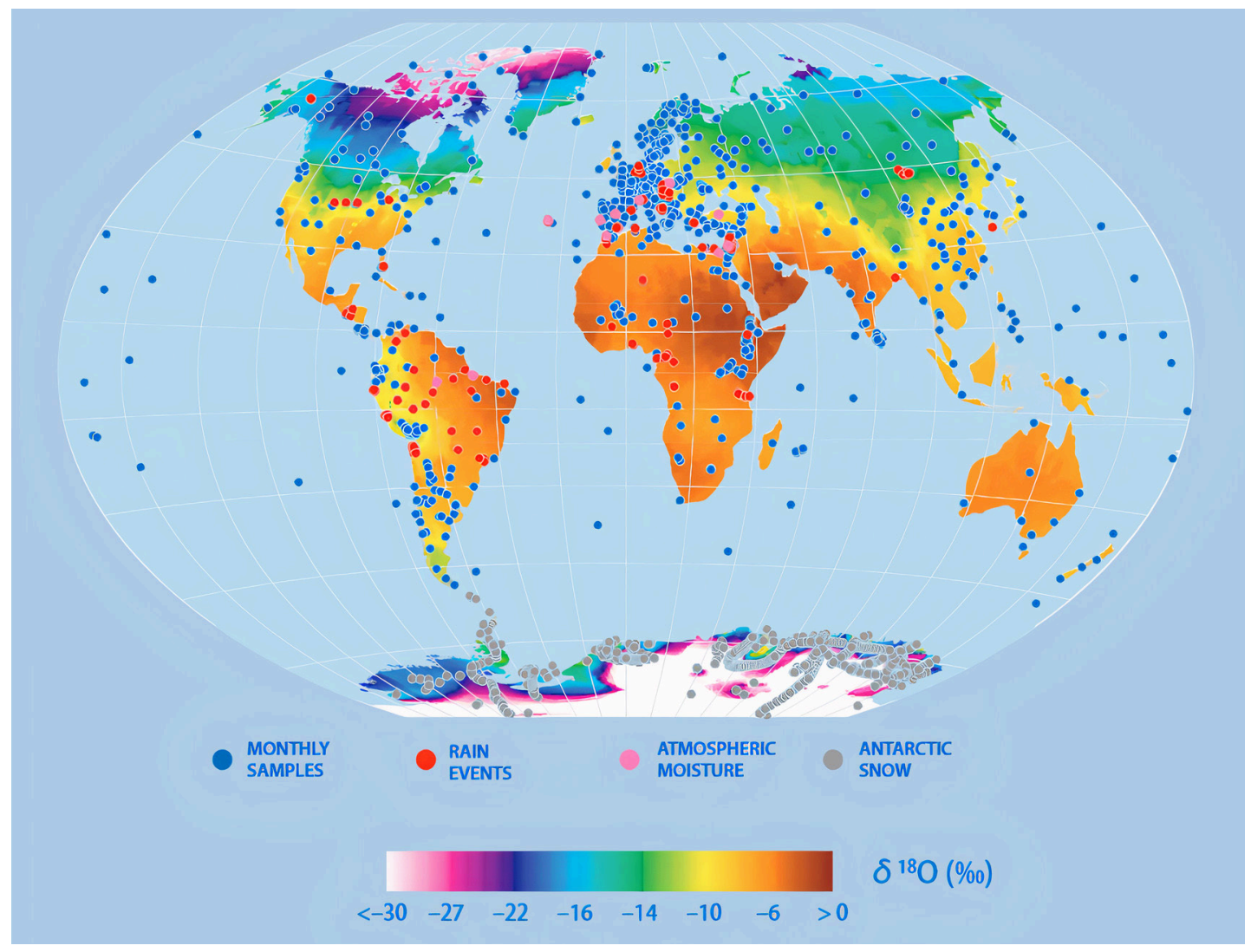

FIGURA 3 - Estações de monitoração da rede GNIP (nem todas ativas). Fonte: IAEA Water Resources Programme - GNIP brochure.

$\mathrm{MBq} / \mathrm{g}$ para concentrações de atividade e $1 \mathrm{GBq}$ para atividades. Os limites regulatórios variam numa extensa faixa entre os países que o fixam: de $76.100 \mathrm{~Bq} / \mathrm{L}$ para a Austrália até $740 \mathrm{~Bq} / \mathrm{L}$ para os Estados Unidos (CANADIAN NUCLEAR SAFETY COMMISSION 2009).

\section{FUNDAMENTAÇÃO TEÓRICA DA APLICAÇÃO DO TRAÇADOR}

Os modelos de parâmetros agrupados (em inglês, lumped parameter models) consistem em equações que tratam o sistema aquífero como um todo, de maneira que, sendo conhecida a data e as concentrações de entrada de algum traçador no sistema aquífero, seu valor de saída (ponto amostrado de descarga) poderá ser previsto a partir de um modelo que reflita a distribuição de tempos de residência (RTD) do sistema aquífero em determinada descarga (MALOSZWESKI \& ZUBER 1982, MALOSZWESKI \& ZUBER 1996, AMIN
\& CAMPANA 1996, ZUBER \& CIEZKOWSKI 1999, ZUBER \& MALOSZWESKI 2001).

A equação que descreve as concentrações de saída do sistema $C(t)$ é dada por uma integral de convolução entre as funções de concentração na entrada do sistema $C_{0}(t)$, função de distribuição de tempo de residência (RTD) $g\left(t-t^{\prime}\right)$ e um fator de correção que leve em consideração reações do traçador utilizado, no caso do trítio, o decaimento radioativo (ZUBER \& MALOSZWESKI 2001).

$$
C(t)=\int_{-\infty}^{t} C_{0}\left(t^{\prime}\right) g\left(t-t^{\prime}\right) \exp \left(-\lambda\left(t-t^{\prime}\right)\right) d t^{\prime}
$$

onde, $t$ é o tempo da coleta da amostra (ano calendário); $t$ ', o tempo da entrada do traçador no aquífero (ano calendário); $\lambda$, a constante de decaimento radioativo (1/tempo, em anos); $\left(t-t^{\prime}\right)$, a idade da parcela de água (em anos).

As premissas envolvidas na construção da equação (1) são de que o traçador é injetado diretamente no fluxo do sistema aquífero, comporta-se de modo conservador (ou é corrigido por decai- 
mento no caso de um traçador radioativo) e realiza seu percurso juntamente com a água subterrânea, assumindo-se que o sistema se encontra em estado estacionário (MALOSZWESKI \& ZUBER 1996).

O tempo médio de residência de um reservatório $(T)$ é definido (Equação 2) como sendo a razão entre o volume $(V)$ do reservatório por sua vazão $(Q)$ (MALOSZWESKI \& ZUBER 1996).

$$
T=\frac{V}{Q}
$$

2.1 Modelos de distribuição de tempo de residência (RTD)

A água subterrânea pode estar presente em uma variedade de tipos de rochas que contêm poros, fissuras e/ou cavidades (GEYH 2000). Em determinadas condições, a água proveniente de precipitação atmosférica, além de outras fontes, pode se infiltrar pelo solo e zona não-saturada e atingir os aquíferos. As áreas do aquífero onde a infiltração de água de chuva ocorre são denominadas de zona de recarga. Dependendo das condições geológicas, a água pode percorrer seu caminho em um aquífero livre ou não-confinado ou, alternativamente, perder o contato com a atmosfera ao entrar em uma porção confinada do aquífero.

Uma vez dentro do aquífero, o armazenamento e a transmissão da água são regulados por propriedades características das rochas (tais como porosidade e condutividade hidráulica) e por condições hidráulicas geradas pela atuação das forças da gravidade e de pressão (expressas por meio do gradiente hidráulico). A circulação de água no aquífero se dá em direção a uma zona de descarga, locais onde a carga hidráulica é menor em relação à zona de recarga e, eventualmente, ela será descarregada em um corpo de água superficial, nascente ou será removida por meio de uma seção filtrante de um poço de bombeamento. Além disso, dependendo das condições, pode ocorrer um troca de água entre aquíferos separados por aquitardos, formações geológicas com menor permeabilidade, na qual águas com diferentes origens podem ser misturadas.

De um modo geral, quanto mais próximo for o ponto de recarga em relação ao de descarga, mais rápida será a trajetória da água dentro do aquífero e menor será seu tempo de residência. Cada uma dessas trajetórias ligando o ponto de recarga e de descarga pode ser descrita por uma linha de fluxo. É importante notar que um determinado ponto de descarga pode receber diferentes linhas de fluxo que convergem para essa área, cujas águas contêm por- ções com tempo de residência diferentes e que podem ser misturadas na descarga.

Os modelos de distribuição de tempo de residência (RTD), também chamados de funções $\mathrm{g}(\mathrm{t})$, funções peso ou função resposta, são caracterizados por equações que descrevem o comportamento de uma molécula do elemento traçador no fluxo subterrâneo. Apesar de se tratarem, basicamente, de uma equação matemática cujos parâmetros são obtidos por meio de ajuste de dados de séries temporais da concentração do traçador nos pontos de recarga e de descarga, o desenvolvimento de cada tipo de modelo RTD pode ser relacionada com tipos diferentes de modelos conceituais de fluxo subterrâneo, como será discutido a seguir. Os principais modelos existentes são os de fluxo em pistão (PFM), fluxo exponencial (EM), fluxo exponencial-pistão (EPM), fluxo parcial exponencial (PEM) e fluxo dispersivo (DM), conforme pode ser visto em ZUBER \& MALOSZWESKI (2001) e AMIN \& CAMPANA (1996).

As equações referentes aos modelos podem ser agrupadas em modelos de uma variável (PFM e EM) ou de duas variáveis (EPM, PEM e DM). A variável tempo médio de residência $(\mathrm{T})$ é requerida em todos os modelos e um parâmetro adicional específico é requerido para os modelos EPM, PEM e DM.

Conforme ressaltado por LEIBUNDGUT et al. (2009), a integral da função RTD sobre todos os tempos de residência possíveis deve ser igual a um, sendo, por isso, a função $g(t)$ também conhecida como função peso.

\subsubsection{Fluxo em pistão (PFM)}

O modelo de fluxo em pistão (PFM) considera que todas as linhas de fluxo possuem o mesmo tempo de trânsito e desconsidera os efeitos de dispersão hidrodinâmica e difusão no sistema em análise (ZUBER \& MALOSZWESKI 2001). A figura 4 ilustra o modelo conceitual em que o modelo

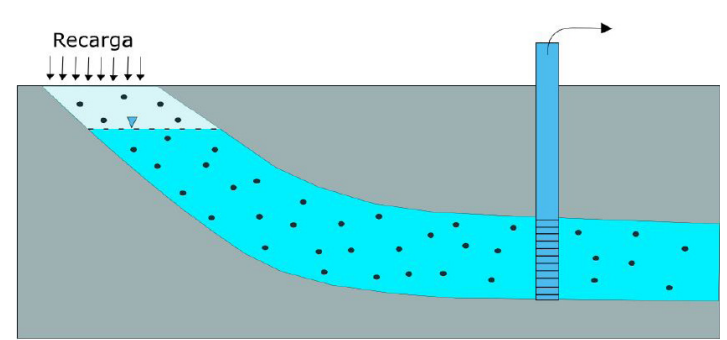

FIGURA 4 - Modelos conceitual para utilização de fluxo em pistão (PFM). 
de fluxo em pistão é aplicável, ressaltando que as linhas de fluxo não se misturam. O modelo PFM pode ser aplicado a aquíferos confinados com área de recarga pequena comparada ao comprimento do aquífero até o ponto de amostragem, ou em aquíferos livres com linhas de fluxo que cruzam o ponto de amostragem através de uma zona discreta (poços com seção filtrante curta) contendo linhas de fluxo de mesma idade.

A função resposta é dada pela função delta de Dirac, definida apenas no intervalo em que seu argumento é igual a zero, resultando em valor unitário, o que significa um pulso instantâneo na saída do sistema contendo toda massa injetada do traçador, corrigida apenas pelo decaimento radioativo (ZUBER \& MALOSZWESKI 2001).

$$
g\left(t-t^{\prime}\right)=\delta\left(t-t^{\prime}-T\right)
$$

onde $t$ é a data da coleta, $t$ ' é a data da entrada e $T$ é o tempo de residência. Conforme pode ser visto na figura 5, em uma curva de distribuição de tempo de residência para um modelo PFM, toda a concentração de saída do traçador situa-se em um intervalo de tempo discreto, sendo sua concentração na saída entendida como uma função do decaimento radioativo ocorrido durante o intervalo de tempo entre a injeção e a saída do traçador no sistema.

A solução analítica do modelo de fluxo em pistão é obtida aplicando-se a equação (3) na equação (1) e resulta em:

$$
C(t)=C_{0}(t-T) \exp (-\lambda T)
$$

\subsubsection{Fluxo exponencial (EM)}

No modelo de fluxo exponencial (EM), a recarga ocorre distribuída por toda extensão do aquí-

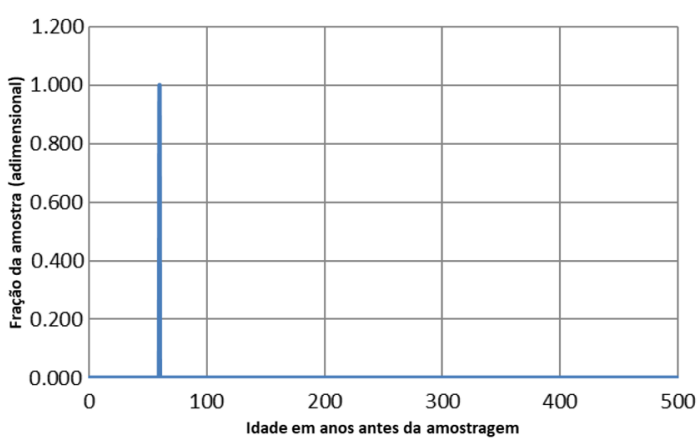

FIGURA 5 - Formato da curva de função de distribuição de tempo de residência $\mathrm{g}\left(\mathrm{t}-\mathrm{t}^{\prime}\right)$ para um modelo PFM hipotético com $\mathrm{T}$ de 60 anos. fero de modo uniforme, sendo este, portanto, considerado um aquífero livre (Figura 6). Além disso, assume-se que as linhas de fluxo caracterizam uma distribuição de tempo de residência exponencial, sendo que, as linhas de fluxo mais curtas possuem tempo de trânsito teóricos igual a zero e as linhas de fluxo mais longas possuem tempos de trânsito teóricos tendendo para o infinito (ZUBER \& MALOSZWESKI 2001). Assume-se também que não há mistura entre as linhas de fluxo ao longo do sistema aquífero a não ser no ponto de amostragem, onde ocorre uma mistura total (MALOSZWESKI \& ZUBER 1996).

Sendo assim, a equação que descreve o modelo de distribuição de tempo de residência exponencial é dada por:

$$
g\left(t-t^{\prime}\right)=\frac{1}{T} \exp \left\lfloor\frac{-\left(t-t^{\prime}\right)}{T}\right\rfloor
$$

O formato da curva $\mathrm{g}\left(\mathrm{t}-\mathrm{t}^{\prime}\right)$ de distribuição das frações da amostra, para um modelo exponencial, com seu respectivo tempo de residência é apresentado na figura 7. Cabe ressaltar que a integral da área abaixo da curva deve retornar o valor igual a 1 .

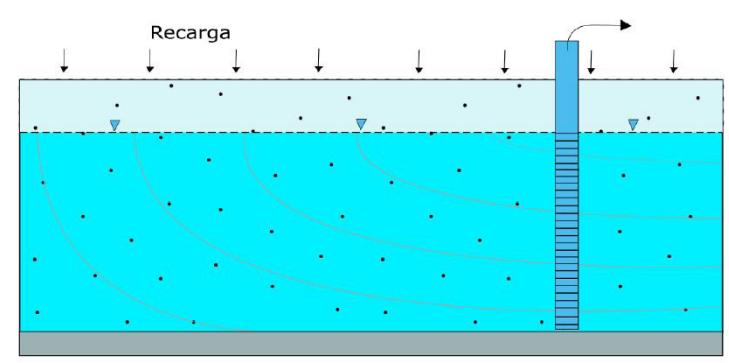

FIGURA 6 - Modelo conceitual esquemático para utilização de fluxo exponencial (EM).

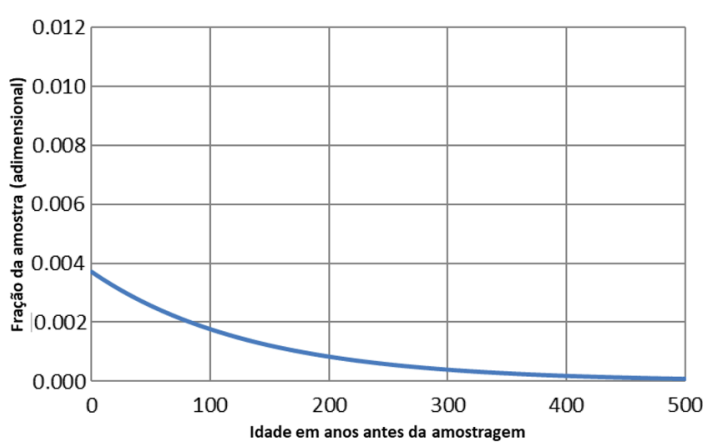

FIGURA 7 - Formato da curva de função de distribuição de tempo de residência $\mathrm{g}\left(\mathrm{t}-\mathrm{t}^{\prime}\right)$ para um modelo EM hipotético com $\mathrm{T}$ de 135 anos. 
Conforme mostrado em JURGENS et al. (2012) a solução da integral de convolução para o modelo exponencial é dada através do somatório de sua solução analítica (Equação 6) para cada incremento de tempo $\Delta \mathrm{t}$, começando da data da amostra subtraída pelo incremento de tempo e progredindo de modo regressivo no tempo, até que as diferenças entre concentrações de saída não sejam menores que 1,0E-6 (em unidade de concentração do traçador):

$$
\begin{gathered}
C(t)=\sum_{t^{\prime}=-\infty}^{t-\Delta t} C_{0}\left(t^{\prime}\right) \frac{1}{T} \frac{1}{\frac{1}{T}+\lambda}\left(\exp \left[-\left\{\frac{1}{T}+\lambda\right\}\left\{t-t^{\prime}-\Delta t\right\}\right]\right. \\
\left.-\exp \left[-\left\{\frac{1}{T}+\lambda\right\}\left\{t-t^{\prime}\right\}\right]\right)
\end{gathered}
$$

\subsubsection{Fluxo exponencial-pistão (EPM)}

O modelo de fluxo combinado exponencial-pistão (EPM) assume que o aquífero é constituído de dois compartimentos em série, sendo um com distribuição de tempos de residência exponencial e o outro com distribuição aproximada por um fluxo em pistão (ZUBER \& MALOSZWESKI 2001). Segundo JURGENS et al. (2012), esse modelo pode ser utilizado para descrever descargas de um aquífero de espessura constante com uma porção a montante não confinada, recebendo uma recarga espacialmente distribuída e estando conectada a uma porção a jusante confinada (ou com recarga desprezível), por onde as linhas de fluxo seguem sem que se misturem até o ponto de amostragem. Conforme pode ser observado na figura 8 , o modelo aquífero do tipo EPM, simplificado a um caso em duas dimensões, é composto por uma área de recarga de comprimento $\mathrm{X}$, seguido de uma parte em que não contribui com a recarga subterrânea de comprimento $\mathrm{X}^{*}$ até o ponto de amostragem. As misturas entre as diferentes linhas de fluxo somente ocorrem no ponto de amostragem, permanecendo imiscíveis ao longo do comprimento do aquífero.

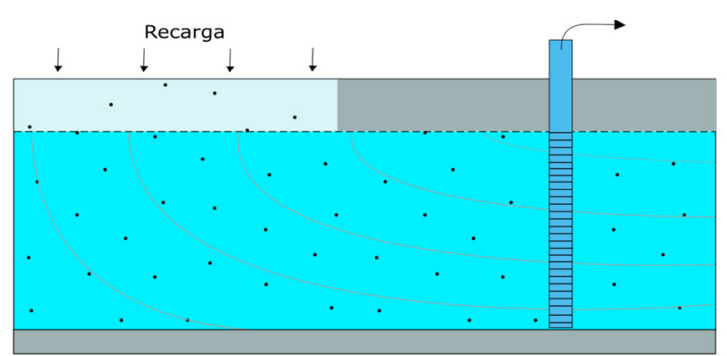

FIGURA 8 - Modelo conceitual esquemático para utilização de fluxo exponencial-pistão (EPM).
A função RTD que descreve o modelo EPM é dada por:

$$
\begin{aligned}
& g\left(t-t^{\prime}\right)=\frac{\eta}{T} \exp \left[-\frac{\eta\left(t-t^{\prime}\right)}{T}+\eta-1\right] \text { para } t \geqslant T\left(1-\frac{1}{\eta}\right) \\
& g\left(t-t^{\prime}\right)=0 \text { para } t \leqslant T\left(1-\frac{1}{\eta}\right)
\end{aligned}
$$

Onde:

$\eta=\frac{\text { volume total }}{\text { volume exponencial }}=\frac{X^{*}+X}{X}=r E P M+1$

O modelo EPM possui dois parâmetros na equação: Tempo médio de residência $(\mathrm{T})$ e razão

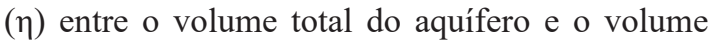
do reservatório regido pelo modelo exponencial. $\mathrm{O}$ valor de $\eta$ é obtido por ajuste e pode ser entendido a partir da razão exponencial-pistão (rEPM), que é interpretado como a razão entre o volume da porção regida pelo modelo exponencial e o volume da porção regida pelo modelo pistão obtido por ajuste do modelo (JURGENS et al. 2012).

O formato da curva $\mathrm{g}\left(\mathrm{t}-\mathrm{t}^{\prime}\right)$ de distribuição das frações da amostra, para um modelo EPM, com seu respectivo tempo de residência é apresentado na figura 9. Nota-se que a saída do traçador no sistema somente começa a ocorrer a partir de um certo intervalo de tempo desde sua entrada. A partir desse intervalo de tempo, as frações que compõem a amostra com tempo de residência superiores tendem a decrescer exponencialmente, de modo que a integral da área sobre a curva resulte em um valor unitário.

As concentrações de saída do traçador são calculadas no modelo EPM usando o somatório da solução analítica da integral de convolução para cada incremento de tempo $\Delta \mathrm{t}$, começando da data da coleta da amostra subtraída por cada incremento de tempo e progredindo, de modo regressivo no

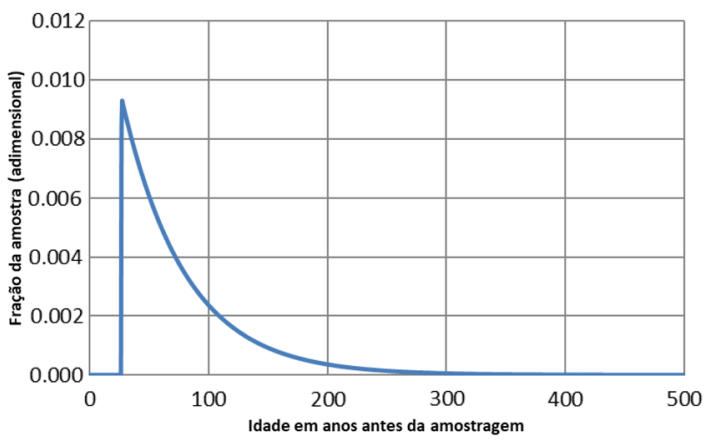

FIGURA 9 - Formato da curva de função de distribuição de tempo de residência $\mathrm{g}\left(\mathrm{t}-\mathrm{t}^{\prime}\right)$ para um modelo EPM hipotético com rEPM $=0,63$ e $\mathrm{T}=80$ anos. 
tempo, até que as diferenças nas concentrações de saída não sejam menores que 1,0E-6 (em unidade de concentração do traçador), similarmente à solução do modelo EM. Conforme mostrado em JURGENS et al. (2012), a solução é dada por:

$$
\begin{aligned}
& C(t)=\sum_{t^{\prime}=-\infty}^{t-\Delta t} C_{0}\left(t^{\prime}\right) \frac{\eta}{T} \frac{1}{T}+\lambda\left(\begin{array}{c}
\exp \left(-\left(\frac{\eta}{T}+\lambda\right)\left(t-t^{\prime}-\Delta t\right)+\eta-1\right) \\
-\exp \left(-\left(\frac{\eta}{T}+\lambda\right)\left(t-t^{\prime}\right)+\eta-1\right)
\end{array}\right), \\
& \text { para } t \geq T\left(1-\frac{1}{\eta}\right) ; \\
& C(t)=0, \text { para } t \leq T\left(1-\frac{1}{\eta}\right)
\end{aligned}
$$

\subsubsection{Fluxo parcial exponencial (PEM)}

O modelo de fluxo parcial exponencial (PEM) pode ser aplicado ao mesmo tipo de aquífero onde é aplicável o modelo exponencial. No entanto, JURGENS et al. (2012) desenvolveram esse modelo para aplicação em casos onde apenas a parte inferior do aquífero é amostrada, como acontece em poços de abastecimento público em que as seções filtrantes são colocadas exclusivamente em porções profundas do aquífero. Nesse modelo, a recarga ocorre por todo o aquífero, no entanto, o ponto de amostragem possui uma profundidade $Z^{*}$ em que não ocorre amostragem. Além disso, misturas entre linhas de fluxo somente ocorrem no ponto de descarga (Figura 10).

A função RTD que descreve o modelo parcial exponencial é dada por:

$$
\begin{gathered}
g\left(t-t^{\prime}\right)=\frac{\eta}{\tau_{a q}} \exp \left(-\frac{t-t^{\prime}}{\tau_{a q}}\right) \text { para } t-t^{\prime} \geq \tau_{a q} \ln (\eta) \\
g\left(t-t^{\prime}\right)=0 \text { para } t-t^{\prime} \leq \tau_{a q} \ln (\eta)
\end{gathered}
$$

Onde:

$$
\begin{gathered}
\eta=\frac{\text { volume total }}{\text { volume amostrado }}=\frac{Z^{*}+Z}{Z}=r P E M+1 \\
\tau_{a q}=\frac{T}{\left(1-\ln \left(1-\frac{Z^{*}}{Z+Z^{*}}\right)\right)}
\end{gathered}
$$

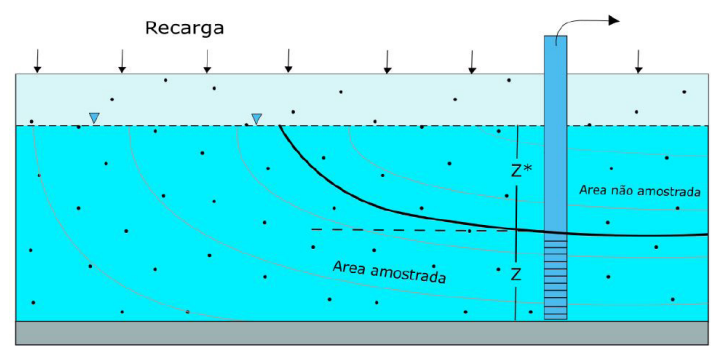

FIGURA 10 - Modelo conceitual esquemático para utilização de fluxo parcial-exponencial (PEM).
Segundo JURGENS et al. (2012), a razão $Z^{*} / Z$ pode ser estimada independentemente do modo de construção do poço e do conhecimento de sua profundidade a partir do ajuste do modelo, sendo que poços com seções filtrantes longas indicam similaridade com o modelo exponencial (EM) e poços com seções filtrantes curtas indicam similaridade com o modelo em pistão (PFM).

O formato da curva $\mathrm{g}\left(\mathrm{t}-\mathrm{t}^{\prime}\right)$ de distribuição das frações da amostra, para um modelo PEM, com seu respectivo tempo de residência é apresentado na figura 11. Nota-se que, assim como mostrado em um modelo do tipo EPM, a saída do traçador no sistema somente começa a ocorrer a partir de um certo intervalo de tempo. A partir desse intervalo, as frações que compõem a amostra com tempo de residência superiores tendem a decrescer exponencialmente, de modo que a integral da área sobre a curva resulte em um valor unitário.

As concentrações de saída do traçador no modelo PEM são calculadas de modo iterativo semelhante à maneira como é realizado para o modelo EPM. A equação que descreve a saída do traçador no sistema é dada por:

$$
\begin{gathered}
C(t)=\sum_{t^{\prime}=-\infty}^{t-\Delta t} C_{0}\left(t^{\prime}\right) \frac{\eta}{\tau_{a q}} \frac{1}{\frac{1}{\tau_{a q}+\lambda}}\left(\begin{array}{c}
\exp \left(-\left(\frac{1}{\tau_{a q}}+\lambda\right)\left(t-t^{\prime}-\Delta t\right)\right) \\
-\exp \left(-\left(\frac{1}{\tau_{a q}}+\lambda\right)\left(t-t^{\prime}\right)\right)
\end{array}\right), \\
\text { para } t-t^{\prime} \geq \tau_{a q} \ln \eta \\
C(t)=0, \text { para } t-t^{\prime} \leq \tau_{a q} \ln \eta
\end{gathered}
$$

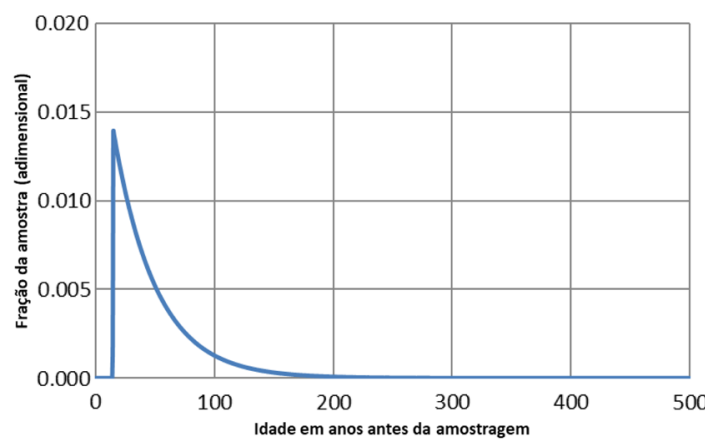

FIGURA 11 - Formato da curva de função de distribuição de tempo de residência $\mathrm{g}\left(\mathrm{t}-\mathrm{t}^{\prime}\right)$ para um modelo PEM hipotético com $\mathrm{rPEM}=0,5 \mathrm{e} \mathrm{T}=50$ anos.

\subsubsection{Fluxo dispersivo (DM)}

O modelo dispersivo é aplicável a qualquer um dos modelos conceituais descritos anteriormente, justificando-se quando as linhas de fluxo nos mode- 
los não possuem a mesma velocidade. Desvios aos modelos anteriores podem ocorrer devido a diferenças entre as velocidades das linhas de fluxo (resultantes de heterogeneidades) que causam a mistura do traçador dentro do aquífero em diversas escalas espaciais, fazendo-se necessário o uso do modelo dispersivo.

O modelo de fluxo dispersivo (DM) é baseado na solução unidimensional da equação de advecção-dispersão para um meio semi-infinito com uma injeção instantânea e detecção do traçador no modo de fluxo (ZUBER \& MALOSZWESKI 2001, JURGENS et al. 2012). O modelo de dispersão possui dois parâmetros: o tempo médio de residência $(T)$ e o parâmetro de dispersão $(D p)$. A equação que descreve o modelo de dispersão é dada por:

$$
g\left(t-t^{\prime}\right)=\frac{1}{T} \frac{1}{\sqrt{4 \pi D p\left(\frac{t-t^{\prime}}{T}\right)}} \exp \left(-\frac{\left[1-\frac{t-t^{\prime}}{T}\right]^{2}}{4 D p\left[\frac{t-t^{\prime}}{T}\right]}\right)
$$

Onde:

$$
D p=\frac{\text { Coeficientededispersão }(D)}{v \cdot x}=\frac{\frac{m^{2}}{s}}{\frac{m}{s} \cdot m}
$$

Segundo ZUBER \& MALOSZWESKI (2001), a variável $D p$ é o parâmetro de dispersão aparente, também entendido como sendo o inverso do número de Peclet, embora não relacionado diretamente com a dispersividade de sistemas subterrâneos e sim com a forma da curva de distribuição de tempos de residência. Conforme explicitado em JURGENS et al. (2012), o parâmetro de dispersão, na prática, descreve o comprimento e a altura da distribuição de tempos de residência e principalmente fornece uma medida da importância relativa da dispersão hidrodinâmica sobre a advecção em função da escala de observação.

O formato da curva $\mathrm{g}\left(\mathrm{t}-\mathrm{t}^{\prime}\right)$ de distribuição das frações da amostra, para um modelo DM, com seu respectivo tempo de residência, é apresentado na figura 12. O formato da curva para o modelo DM assemelha-se a uma forma suavizada do modelo EPM ou PEM, sendo que nesse modelo as concentrações aumentam e diminuem de maneira gradual e contínua, fato este que normalmente é mais condizente com sistemas naturais.

O modelo de dispersão pode ser calculado por integração numérica de acordo com a equação seguinte para cada incremento de $\Delta \mathrm{t}$, começando da data da amostra subtraída por cada incremento de tempo, de modo regressivo, até que as diferenças entre as concentrações de saída não sejam menores que 1,0E-7 (em unidade de concentração do traçador), conforme mostrado em KINZELBACH et al. (2002) e JURGENS et al. (2012).

$$
C(t)=\frac{1}{\sqrt{4 \pi D p}} \exp \left(\frac{1}{2 D p}\right) \sum_{t^{\prime}=-\infty}^{t-\Delta t} C_{0}\left(t^{\prime}\right) \int_{x_{2}}^{x_{1}} x^{\frac{3}{2}} \exp \left(-a x-\frac{b}{x}\right) d x
$$

Onde:

$$
\begin{aligned}
& a=\lambda T+\frac{1}{4 D p} ; b=\frac{1}{4 D p} ; x=\frac{t-t^{\prime \prime}}{T} \\
& x_{1}=\frac{t-t^{\prime}}{T} ; x_{2}=\frac{t-t^{\prime}-\Delta t}{T} .
\end{aligned}
$$

\subsection{Função de entrada do trítio}

As variações sazonais nas concentrações de trítio nas precipitações dificultam o cálculo da função de entrada $\left(\mathrm{C}_{0}(\mathrm{t})\right)$ utilizada nos modelos de parâmetros agrupados. MALOSZWESKI \& ZUBER (1996) sugerem que o melhor método de se estimar essa função é a partir da média anual da concentração observada em cada mês ponderada pela precipitação mensal e pela taxa de infiltração, conforme mostrado na equação:

$$
C_{0}(\text { anual })=\frac{\sum_{i=1}^{12} C_{i} \alpha_{i} P_{i}}{\sum_{i=1}^{12} \alpha_{i} P_{i}}
$$

Onde $C_{i}, \alpha_{i}, P_{i}$, são, respectivamente, as concentrações mensais de trítio na precipitação (UT), a fração mensal da precipitação efetivamente infiltrada (adimensional) e a precipitação mensal ( $\mathrm{mm}$ ) observada.

Conforme mostrado em MALOSZWESKI \& ZUBER (1996), as concentrações nas precipitações $\left(C_{i}\right)$ podem ser obtidas no site da Agência Internacional de Energia Atômica (IAEA) a partir da sua rede de monitoramento GNIP (Global Network Isotope in Precipitation). As estações estão espalhadas em diversos continentes do mundo, sendo que as concentrações locais podem ser obti-

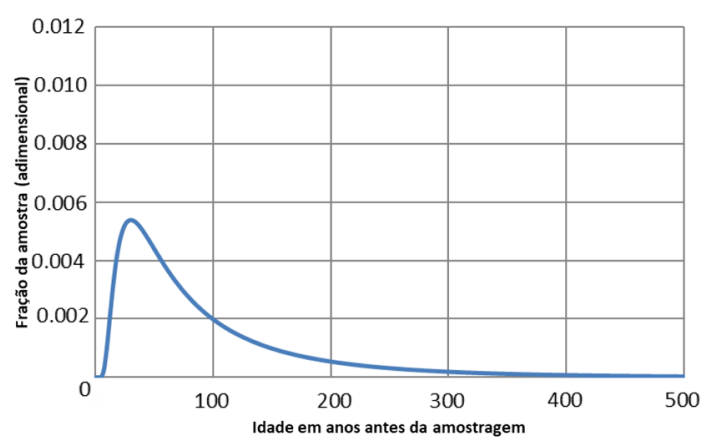

FIGURA 12 - Formato da curva de função de distribuição de tempo de residência $\mathrm{g}\left(\mathrm{t}-\mathrm{t}^{\prime}\right)$ para um modelo DM hipotético com $\mathrm{Dp}=0,5$ e $\mathrm{T}=100$ anos. 
das a partir da correlação entre diferentes estações. Os valores das taxas de precipitações podem ser obtidos a partir de estações meteorológicas locais.

O valor da fração mensal da precipitação efetivamente infiltrada é o maior complicador da equação, sendo que os autores apontam que, no caso de climas temperados do hemisfério norte, ocorre uma diferenciação entre os valores de $\alpha_{i}$ nos meses de inverno e de verão. No caso específico do hemisfério norte, a recarga ocorre preferencialmente nos meses de inverno e, portanto, segundo MALOSZWESKI \& ZUBER (1996), o coeficiente de infiltração $(\alpha)$ no verão pode ser considerado, de forma aproximada, como uma fração do coeficiente de infiltração no inverno, reduzindo o número de incógnitas $\left(\alpha_{\mathrm{i}}\right)$ para apenas uma, conforme descrito pela equação:

$$
C_{0}(\text { anual })=\frac{\left[\left(\alpha \sum C_{i} P_{i}\right)_{s}+\left(\sum C_{i} P_{i}\right)_{w}\right]}{\left[\alpha\left(\sum P_{i}\right)_{s}+\left(\sum P_{i}\right)_{w}\right]}
$$

Onde os subscritos "s" e "w", se referem aos meses "i" do verão e inverno, respectivamente. Deve-se observar que, no caso de climas tropicais a subtropicais do hemisfério sul, a recarga ocorre preferencialmente nos meses de verão e, portanto, a substituição dos índices relativos ao verão na equação (19) por valores referentes ao inverno deve ser feita para sua correta utilização.

O trabalho de GRABCZAK et al. (1984) desenvolve uma metodologia para estimativa do valor de $\alpha$ para regiões de climas temperados do hemisfério norte, a partir de dados dos isótopos estáveis deutério ou oxigênio-18. Como conclusão, o autor mostra que, apesar de uma longa série de valores de deutério ou oxigênio-18 nas precipitações serem necessários para estimar $\alpha$ com acurácia, uma aproximação grosseira do parâmetro $\alpha$, a partir de uma série histórica relativamente curta já é suficiente para obter boa aproximação do parâmetro. $\mathrm{O}$ autor ressalta que os erros nas estimativas da função de entrada são sempre menores quando se considera $\alpha=1$, ao invés de $\alpha=0$.

Segundo MALOSZWESKI \& ZUBER (1982), em alguns casos é impossível obter um ajuste das concentrações observadas na saída do sistema aquífero sem considerar a presença de uma fração de "água morta" (água livre de trítio, por exemplo), sendo importante inserir pelo menos dois influxos no sistema analisado. Se a fração de água no ponto de amostragem livre de traçador radioativo é chamada de $\beta$, então $(1-\beta) . C_{0}(t)$ pode ser considerado na integral de convolução (Equação 1 ) ao invés de $\mathrm{C}_{0}(\mathrm{t})$. Isso significa que a componente não radioativa foi recarregada sobre condições climáticas diferentes da componente radioativa, refletindo, portanto, composições de isótopos estáveis (deutério e oxigênio-18) diferentes entre as frações. Sendo assim, os autores apontam que o parâmetro $\beta$ pode ser obtido a partir da composição de isótopos estáveis das diferentes parcelas de acordo com a equação:

$$
\beta=\frac{\left(\delta^{m}-\delta^{r}\right)}{\left(\delta^{n r}-\delta^{r}\right)}
$$

Onde $\delta$ é a composição de deutério ou oxigênio-18 expressa na notação delta e o índice "m" refere-se à água que contém a mistura. Os índices " $r$ " e "nr" referem-se à água com a componente radioativa e sem a componente radioativa, respectivamente.

Apesar da rede de monitoramento GNIP (Global Network Isotope in Precipitation) estar espalhada por todo o globo com pontos de monitoramento de oxigênio-18, deutério e trítio, diversas áreas não possuem dados diretos de monitoramento. Sendo assim, ZHAI et al. (2013) evidenciam que regiões específicas que não possuem dados diretos de monitoramento de longo prazo, podem ser supridas de informações de duas maneiras: utilizando os dados diretos de outra região, aplicando-os à área em questão, ou calculando a função de entrada a partir de algum método baseado nos dados de outra estação de monitoramento.

Conforme mostrado em ZHAI et al. (2013), alguns dos métodos que permitem a reconstrução da série histórica do trítio para determinado local são: Método da curva de referência dupla (DRCM), Método da triangulação (TM) e Método da correlação $(\mathrm{CM})$, descritos a seguir.

2.2.1 Método da curva de referência dupla (DRCM)

O método da curva de referência dupla (DRCM), desenvolvido por DONEY et al. (1992), baseia-se em dados de 250 estações GNIP ao redor do mundo, resultando em um modelo em escala global para a previsão das concentrações anuais médias de trítio durante o período entre 1960-1986. O método utiliza a análise de fatores para estimar o melhor conjunto de curvas de referência para reconstruir as concentrações de trítio nas precipitações. A concentração média anual de trítio em uma determinada estação pode ser considerada como sendo uma combinação linear de duas curvas de referências denominadas $\bar{C} \mathrm{p}(\mathrm{t}, 1)$ e $\bar{C} \mathrm{p}(\mathrm{t}, 2)$, segundo a equação: 


$$
C p(t)=f_{1} \bar{C} \mathrm{p}(\mathrm{t}, 1)+f_{2} \bar{C} \mathrm{p}(\mathrm{t}, 2)+\epsilon_{a}(\mathrm{t})
$$

Onde $\mathrm{Cp}(\mathrm{t})$ é a concentração média anual de trítio na estação de interesse, $f_{1}$ e $f_{2}$ são coeficientes únicos para cada estação e $\epsilon_{a}(\mathrm{t})$ é a função erro que mede o desvio do valor previsto em relação ao valor observado na estação. Os valores das curvas de referências $\overline{C p}$ e dos coeficientes $f_{1}$ e $f_{2}$ de cada estação utilizada no trabalho são disponibilizados pelo autor na forma de tabelas ao longo de seu texto.

\subsubsection{Método da triangulação (TM)}

O método da triangulação (TM), proposto por CELLE-JEANTON et al. (2002), caracteriza-se pela predição das concentrações médias anuais de trítio nas precipitações de uma determinada estação em que se deseja reconstruir uma série histórica com base nos dados de estações vizinhas. Para isso, são necessárias três estações circundantes que possuam uma série histórica de monitoramento dita satisfatória.

Considerando uma estação D em que se deseja reconstruir uma série histórica, rodeada pelas estações $\mathrm{A}, \mathrm{B}$ e $\mathrm{C}$ com os respectivos teores de trítio $T_{A}, T_{B}$ e $T_{C}$, sua concentração de trítio $\left(T_{D}\right)$ pode ser obtida pela equação:

$$
T_{D}=f_{A} T_{A}+f_{B} T_{B}+f_{C} T_{C}
$$

Onde:

$$
\begin{aligned}
f_{A}= & \frac{\left(L_{C}-L_{B}\right)\left(l_{B}-l_{D}\right)-\left(l_{C}-l_{B}\right)\left(L_{B}-L_{D}\right)}{\left(L_{C}-L_{B}\right)\left(l_{B}-l_{A}\right)-\left(l_{C}-l_{B}\right)\left(L_{B}-L_{A}\right)} \\
f_{B}= & \frac{\left(L_{C}-L_{A}\right)\left(l_{A}-l_{D}\right)-\left(l_{C}-l_{A}\right)\left(L_{A}-L_{D}\right)}{\left(L_{C}-L_{A}\right)\left(l_{A}-l_{B}\right)-\left(l_{C}-l_{A}\right)\left(L_{A}-L_{B}\right)} \\
f_{C}= & \frac{\left(L_{B}-L_{A}\right)\left(l_{A}-l_{D}\right)-\left(l_{B}-l_{A}\right)\left(L_{A}-L_{D}\right)}{\left(L_{B}-L_{A}\right)\left(l_{B}-l_{C}\right)-\left(l_{B}-l_{A}\right)\left(L_{B}-L_{C}\right)}
\end{aligned}
$$

Sendo que que $\mathrm{L}_{\mathrm{A}, \mathrm{B}, \mathrm{C}, \mathrm{D}}$ e $1_{\mathrm{A}, \mathrm{B}, \mathrm{C}, \mathrm{D}}$ referem-se às latitudes e longitudes dos pontos $A, B, C$ e $D$, respectivamente, dadas em grau decimal.

\subsubsection{Método da correlação (CM)}

O método da correlação $(\mathrm{CM})$ reconstrói a série histórica do trítio na região de interesse a partir da correlação entre as concentrações de trítio locais e as concentrações em uma estação contendo uma série histórica de longa duração. Segundo ZHAI et al. (2013), o método da correlação é atrativo devido ao fato de que séries históricas de trítio podem ser obtidas a partir da rede GNIP, permitindo reconstruir séries históricas de qualquer região através de uma simples correlação. No entanto, o autor destaca que uma limitação do método é que, na região de estudo, deve-se ter disponível em um determinado intervalo de tempo medidas das concentrações de trítio para que a correlação com outra estação possa ser realizada. Cabe ressaltar que essa metodologia é amplamente empregada em estudos hidrológicos para reconstrução de séries históricas de precipitações em regiões com escassez de informações, no entanto, nesses estudos a variável de interesse é o acumulado de chuva de um período.

2.3 Tempo médio de residência a partir do ajuste de série temporal de dados de trítio

O processo de obtenção do tempo médio de residência a partir da análise de séries temporais consiste basicamente na calibração de uma curva de distribuição de tempo de residência que melhor se ajusta aos dados (MALOSZWESKI \& ZUBER 1996). Cabe ressaltar que, conforme mostrado por MALOSZWESKI \& ZUBER (1982), não existe um critério objetivo para o ajuste de curvas, sendo esse processo não tão quantitativo.

São diversos os softwares utilizados para modelagem dos dados isotópicos, sendo os mais conhecidos LUMPY, FLOWPC e TracerLPM. Dentre os softwares citados o TracerLPM, elaborado por JURGENS et al. (2012) e disponibilizado pela USGS (United States Geological Survey), vem sendo amplamente utilizado em diversos trabalhos. Segundo JURGENS et al. (2012), o software TracerLPM é uma plataforma baseada em Excel ${ }^{\circledR}$ (2007 ou superior) para a estimativa de funções de distribuição de tempo de residência de traçadores ambientais, utilizando os modelos de parâmetros agrupados. Os ajustes dos modelos de distribuição de tempo de residências discutidos nos itens seguintes foram feitos por meio deste software.

Todos os modelos de distribuição de tempo de residência discutidos no item 2.1 (PFM, EM, EPM, DM) utilizam o tempo médio de residência (T) como variável principal. No entanto, alguns dos modelos de distribuição de tempo de residência (RTD) requerem parâmetros adicionais à variável $T$, como é o caso dos modelos exponencial-pistão (EPM) e dispersivo (DM), sendo obtidos, portanto, a partir do processo de calibração de curvas aos dados de trítio no tempo. Os parâmetros $\eta$ $=1+$ rEPM para o modelo EPM e de dispersão $D p$ para o modelo DM podem ser obtidos com base na calibração do melhor ajuste de curvas de distribuição de tempo de residência sobre dados de amos- 
tras de trítio ao longo do tempo em descargas na região de estudo.

\section{APLICAÇÕES DE TRÍTIO AMBIENTAL EM HIDROGEOLOGIA}

O trabalho de MALOSZEWESKI \& ZUBER (1982) pode ser entendido como uma base fundamental para os trabalhos posteriores que utilizam os modelos de parâmetros agrupados. Segundo os autores, os modelos de fluxo para interpretação de experimentos com traçadores foram desenvolvidos principalmente na área da engenharia química. Porém, os autores ressaltam que, desde os trabalhos pioneiros, diversas confusões ocorreram na interpretação de dados ambientais de radioisótopos utilizando modelos de distribuição de tempo de residência. Isso aconteceu devido à falta de distinção entre conceitos básicos como fluxo de massa e fluxo volumétrico através do sistema e as considerações relacionadas ao movimento do traçador.

MALOSZEWESKI \& ZUBER (1982) definem os termos concentração residente (CR), que expressa a massa de soluto $(\Delta \mathrm{m})$ por unidade de volume de fluido $(\Delta \mathrm{V})$ contido no sistema em um dado instante, e concentração de fluxo (CF), que expressa a razão de fluxo do soluto $(\Delta \mathrm{m} / \Delta \mathrm{t})$ com o fluxo volumétrico da solução $(\mathrm{Q}=\Delta \mathrm{V} / \Delta \mathrm{t})$. Segundo os autores, o termo CR é a concentração média ponderada por uma área de uma seção do sistema transversal ao fluxo, enquanto CF é a concentração média ponderada pelo fluxo volumétrico através de uma seção transversal do sistema. Os valores de CR serão diferentes dos valores de CF sempre que as linhas de fluxo com diferentes velocidades possuírem diferentes concentrações, ou quando ocorrer um gradiente de concentração ao longo das linhas de fluxo, resultando em um sistema dispersivo, o qual tem sua fundamentação matemática amplamente discutida em KREFT \& ZUBER (1978).

Além destes, diversos outros parâmetros e conceitos são discutidos em MALOSZEWESKI \& ZUBER (1982), sendo definido nesse trabalho o termo "tempo de renovação" do aquífero, que significa a razão entre o volume do reservatório pelo fluxo volumétrico de todo o sistema. Os autores comparam e reavaliam diversos estudos anteriores utilizando os diferentes modelos (PFM, EM, EPM, DM e outros) e os conceitos básicos por trás destes, que em muitos trabalhos ante- riores foram suprimidos e levaram a conclusões equivocadas.

DINÇER \& DAVIS (1984) demonstram algumas das aplicações de isótopos ambientais como traçadores em hidrologia, com destaque para as de transporte de umidade em solos, modelos de misturas e evapotranspiração em lagos e pântanos, movimentação glacial, fluxo de água subterrânea e transporte de contaminante em água subterrânea. Segundo os autores, os isótopos ambientais radioativos (trítio e carbono-14, por exemplo) são comumente utilizados para calcular fluxos de águas subterrâneas assumindo modelos pré-concebidos. O modelo mais utilizado era o de fluxo em pistão, porém, na maior parte dos casos esse modelo não refletia o modelo conceitual observado, mas mesmo assim era utilizado devido ao escasso recurso computacional da época. Conforme os autores, com o passar dos anos, modelos baseados na equação de dispersão ou modelos combinados (exponencial-pistão, linear-exponencial, dentre outros) se tornaram aplicáveis e as simplificações se tornaram desnecessárias.

MALOSZEWSKI \& ZUBER (1996) apresentam exemplos de casos em que se utilizaram dados de trítio para interpretação de sistemas aquíferos a partir de modelos de parâmetros agrupados. Segundo os autores, são necessárias no mínimo duas medidas do traçador em análise, espaçadas no tempo, para que uma estimativa da curva de distribuição de tempo de residência seja possível. Os autores apresentam estimativas de parâmetros dos aquíferos feitas a partir da modelagem de dados de trítio e obtenção de tempo de residência para aquíferos porosos e fissurais em diferentes regiões do mundo e com distintos graus de complexidade, evidenciando a robustez do método e as aproximações razoáveis de parâmetros físicos dos aquíferos, comparadas a outras metodologias que permitem obter esses valores. Quando as medidas do traçador se encontram em tempos muito próximos entre si ou se tenha apenas uma medida, uma boa prática é calcular o tempo de residência considerando a média entre os valores obtidos para os modelos PFM e EM. Essa prática é adotada tendo em vista que esses modelos são compreendidos como casos extremos e opostos que dificilmente ocorrem puramente na natureza, sendo o valor real comumente intermediário aos fornecidos por esses modelos.

MALOSZEWSKI et al. (2002) utilizam a modelagem de dados de trítio e oxigênio-18 para identificar o sistema de fluxo do aquífero cárs- 
tico-fissural-poroso denominado de Schneealpe (Áustria), composto por calcários e dolomitos do Triássico e que é usado como abastecimento de água potável da cidade de Viena. $\mathrm{O}$ aquífero cárstico é caracterizado por dois sistemas de fluxo paralelamente interconectados, sendo o primeiro um aquífero poroso-fissural e o segundo um aquífero puramente cárstico. Segundo os autores, a água entra no sistema aquífero Schneealpe através de canais de drenagem onde os volumes são divididos em parcelas para cada sistema de fluxo e finalmente drenados pelas nascentes. Um modelo dispersivo foi aplicado para interpretação dos dados de trítio do sistema fissural-poroso durante os períodos de estiagem (fluxo de base) e um modelo do tipo pistão foi utilizado para tratar os dados de oxigênio-18 que oscilam sazonalmente, devido à presença de dutos cársticos que conectam o aquífero à superfície.

O trabalho de CORCHO ALVARADO et al. (2009) utilizou o trítio para identificar fluxos verticais a partir de poços com longas seções filtrantes, baseado na premissa de uma estratificação do trítio no aquífero, onde sua concentração é maior próximo à superfície e chega a zero em certa profundidade. Os autores utilizam em seu estudo um poço de abastecimento situado no aquífero Fontainebleu Sands localizado na bacia hidrográfica de Paris (França). O trabalho consistiu na construção de um perfil do trítio a partir das seções filtrantes do poço analisado e uma comparação com o perfil de temperatura. Os resultados mostraram que a distribuição de idades das amostras de água subterrânea pode ser tendenciosa em relação às idades das águas subterrâneas dos poços vizinhos, devido ao fenômeno de fluxo preferencial através das seções filtrantes, podendo resultar em uma estimativa errônea dos parâmetros hidráulicos do aquífero em um poço de amostragem, devido à interferência de outros poços.

O trabalho de SOLDER et al. (2016) utiliza dados de isótopos ambientais (gases nobres, trítio, gases industriais, isótopos estáveis e carbono-14), além de informações hidrogeológicas, para determinar o tempo médio de residência baseado em modelos de parâmetros agrupados para modelagem de 19 grandes nascentes distribuídas através da Bacia do Alto Rio Colorado, EUA. Os autores utilizam valores previstos dos tempos médios de residência para avaliar o padrão e o tempo gasto até a resposta do sistema subterrâneo aos períodos de stress hidráulicos. Além disso, fizeram uso de análise estatística dos tempos médios de resi- dência, registros históricos de descargas das nascentes e um índice hidrológico de seca (Palmer Hydrological Drought Index). A interpretação dos dados permitiu concluir que as descargas subterrâneas no fluxo de base do rio Colorado provavelmente irão responder na ordem de poucos anos às mudanças climáticas atuais e aos bombeamentos no aquífero.

Em um contexto tropical de altas altitudes, nos úmidos páramos andinos, MOSQUERA et al. (2016) realizaram uma modelagem baseada em dados isotópicos de oxigênio-18 coletados por um período de 3 anos em precipitações e córregos. Os autores buscaram obter a idade dos fluxos superficiais e uma correlação entre as feições morfométricas com o tempo de residência dos fluxos das bacias hidrográficas. Os modelos de distribuição utilizados foram o exponencial, exponencial-pistão, dispersivo, modelo gama e o modelo de reservatório linear paralelo em dois (os dois últimos não abordados no presente trabalho). $\mathrm{O}$ modelo que melhor descreveu o fluxo de base da bacia foi o exponencial, além disso, evidenciou-se uma forte correlação entre a condutividade elétrica média e o tempo médio de residência dos córregos, indicando uma maneira econômica de se calcular o tempo médio de residência, em nível local. Além disso, observou-se uma correlação inversamente proporcional entre a inclinação média da bacia e o tempo médio de residência.

Buscando avaliar a distribuição especial do trítio nas águas subterrâneas de Fukushima após o acidente nuclear ocorrido em março de 2011, KASHIWAYA et al. (2017) analisaram águas subterrâneas de diversos poços de bombeamento da região estudada. Os autores observaram teores de trítio mais elevados nas águas subterrâneas próximo à região do acidente. Especificamente, poços de pequenas profundidades apresentaram águas com as maiores concentrações de trítio. Isso permitiu os autores concluírem que as porções mais profundas dos aquíferos não foram imediatamente afetadas pelo acidente nuclear, porém as porções mais superficiais receberam recargas de precipitações concentradas em trítio proveniente do acidente nuclear. As altas concentrações de trítio nas precipitações ocorridas nas 5 primeiras semanas após o acidente foram rapidamente dissipadas e as concentrações nas águas subterrâneas foram fortemente misturadas e diluídas.

O trabalho de LINDSEY et al. (2019) utilizou o trítio para classificar as águas subterrâneas dos EUA em modernas, misturadas e pré-moder- 
nas. Para isso, os autores se basearam no fato de que águas recarregadas antes de 1953 (início dos testes nucleares) possuem teores de trítio muito inferiores a águas recarregadas após o pico de concentrações de trítio nas precipitações. Assim, foi possível calcular valores limites para as concentrações de trítio que indicam se determinada água foi recarregada antes de 1953 ou após o pico (bomb-peak), ocorrido por volta de 1965. Com isso, é possível reconhecer um intervalo onde as águas podem ser compreendidas como sendo compostas por uma mistura entre águas modernas e pré-modernas. Algumas limitações quanto ao método de classificação são apontadas, principalmente para águas que possuem concentrações no limiar da classificação entre modernas e misturadas. Além disso, os efeitos de dispersão em águas subterrâneas não são considerados, sendo os valores dos limiares calculados com base em um modelo puramente em pistão.

Em um contexto cárstico na região das montanhas Jura, na Suíça, AFFOLTER et al. (2020) utilizaram o trítio $(\lambda=12,3$ anos $)$ e o berilo-7 ( $\lambda$ $=53,2$ dias) para identificar a origem e tempos de percolação de águas que gotejam na Caverna Milandre com a finalidade de interpretar registros de alta resolução em espeleotemas. Ambos os isótopos são produzidos em sua maioria na estratosfera durante os meses da primavera e suas concentrações são fortemente diluídas durante os meses de inverno, devido à umidade proveniente do Oceano Atlântico nesse período. Para representar um modelo cárstico de dupla porosidade utilizou-se um modelo de binário dispersivo para representar misturas de fluxos rápidos e fluxos lentos. Os resultados mostram que a idade da componente de fluxo rápido é menor que 180 dias, enquanto a de fluxo lento corresponde a um intervalo de 5,5 a 6,6 anos. Os resultados são compatíveis com testes de traçadores realizados em áreas a montante da região estudada. Os autores ainda sugerem que futuros estudos relacionando os registros históricos das concentrações de trítio e a escala regional de transporte atmosférico podem fornecer importantes informações sobre o registro histórico de isótopos estáveis.

No Brasil, os trabalhos com trítio efetivamente iniciaram-se em 1968 no CDTN ( na época, Instituto de Pesquisas Radioativas - IPR), graças à iniciativa pioneira do Prof. Maurício Mendes Campos, que, com o apoio da IAEA, foi a Israel e de lá trouxe a metodologia de análise do radioisótopo. Inicialmente, o trítio em amostras de água era contado em um sistema de contadores proporcionais, mas, com o decréscimo dos teores do trítio antropogênico no meio ambiente, sistemas de concentração eletrolítica (SCE) com capacidades crescentes foram sendo introduzidos, assim como novos sistemas de blindagem. No final da década de 1990 foi construído um novo prédio dedicado exclusivamente à análise do ${ }^{3} \mathrm{H}$ com uma característica singular: a sala de contagem, além de semienterrada, é totalmente involucrada em um sistema de paredes, teto e piso duplos, em que o espaço intersticial é preenchido por uma camada de água. Essa câmara blindada, alcunhada de "Titanic", reduziu drasticamente o background. Atualmente, o Laboratório de Trítio Ambiental (LTA) do CDTN é o único a trabalhar com trítio ambiental no país, atingindo limites de detecção de 0,2 UT. Em 2020, o laboratório recebeu da IAEA um sistema de concentração eletrolítica compacto e automatizado que possibilita alcançar fatores de concentração mais elevados que os atuais e se propõe a medir com precisão amostras de água com concentrações de até 0,05 UT.

O trítio ambiental tem sido usado no Brasil para separar as águas recentes das mais antigas e na determinação de tempos médios de residência em poços de abastecimento. Na falta de uma curva de entrada de trítio válida para a região abordada, é usada uma série de valores construída com medidas de precipitações em estações mais próximas, ajustando-se os parâmetros do modelo de distribuição de tempo de residência aos dados do traçador. Além disso, na ausência de uma série temporal que permita ajustar os modelos das curvas de distribuição de tempo de residência aos dados do traçador, em geral, assume-se a premissa de que o modelo exponencial é representativo do fluxo do reservatório subterrâneo. Como exemplos desses trabalhos podem ser citados os de MINARDI et al. (2008) no aquífero Bauru do município de Araguari, MG, e de MOURÃO (2007) e CARVALHO (2012) no aquífero Cauê, Serra da Moeda, MG.

O trabalho de BEDMAR \& SILVA (1980) é um bom exemplo de como a falta de uma série temporal adequada de dados para uma aplicação mais precisa do método foi compensada pelo uso do conhecimento hidrogeológico da área para aumentar a confiança na estimativa de tempos de residência. Os autores estimaram os tempos de residência para 53 amostras de água subterrânea do aquífero cárstico na região de Jaíba, norte do estado de Minas Gerais, usando o modelo expo- 
nencial. Além de considerações sobre o modelo conceitual de fluxo já conhecido para a área, os autores utilizaram dados de trítio de um ano antes em três poços para confirmar as estimativas realizadas.

SILVA \& COTA (2021) utilizaram os teores de trítio medidos em quatro poços nos trabalhos de MOURÃO (2007) e CARVALHO (2012) para calibrar os parâmetros dos modelos EM, EPM e DM e estimar os erros relativos da estimativa. Com base nesses erros, foi possível concluir que o modelo exponencial não representava bem os dados para esse aquífero e que o modelo EPM permitia um melhor ajuste, pois para três dos poços, o fluxo era parcialmente explicado pelo componente em pistão (modelo PFM). Além disso, o ajuste dos modelos a dados de séries temporais forneceu indícios do grau de vulnerabilidade de cada poço à presença de um contaminante conservativo no sistema, permitindo a estimativa do tempo de chegada no poço e o tempo para remoção de uma determinada fração do traçador.

\section{APLICAÇÕES DO TRÍTIO AMBIENTAL EM BACIAS HIDROGRÁFICAS}

O trabalho de STEWART et al. (2010) mostra como o uso de isótopos estáveis na modelagem das curvas de distribuição de tempo de residência podem contribuir para o conceito de idade do fluxo de água superficiais. Resultados obtidos com o uso de isótopos estáveis (oxigênio-18) e trítio em diferentes escalas de bacias hidrográficas mostram que a maior parte das águas que compõem um fluxo superficial é muito velha, indicando uma forte contribuição dos aquíferos para os rios. Assim, os autores sugerem comparar e entender quais fatores geológicos nas diferentes bacias podem fornecer grandes diferenças nos valores calculados utilizando os diferentes isótopos. É importante ressaltar que as diferenças nas curvas de distribuição de tempo de residência a partir das diferentes metodologias podem impor grandes erros de previsões nos valores de armazenamento das bacias, escondendo parte de um importante sistema de alimentação subterrânea para as drenagens de bacias hidrográficas.

O trabalho de MORGENSTERN et al. (2010) evidencia o caráter transiente do tempo médio de residência em uma bacia hidrográfica em função de sua condição de fluxo. Os autores utilizaram como exemplo uma pequena bacia hidrográfica localizada em uma região domi- nada por pecuária. Durante os meses de inverno (alta precipitação) o tempo médio de residência varia entre 2 a 5 anos, aumentando para 30 a 40 anos durante os meses de verão (baixa precipitação). Durante secas prolongadas, foi observado que águas com tempo de residência superiores a 100 anos podem ser drenadas. Os resultados permitiram observar que o armazenamento de água subterrânea na bacia é 2,3 vezes maior que o fluxo hídrico anual da bacia. Além disso, os autores mostram que, devido à estabilização dos teores de trítio nas precipitações, é possível obter o tempo médio de residência das águas subterrâneas da bacia com uma única medida de trítio ao longo do tempo, sem a necessidade de uma longa série histórica.

A importância da obtenção de tempos de trânsito utilizando trítio em sistemas hidrológicos é evidenciada por STEWART \& MORGENSTERN (2016). Isso se deve ao fato de que a forma como são estudadas as águas superficiais e subterrâneas são muito diferentes devido às diferenças entre características geométricas e escalas de tempos para bacias e aquíferos. Assim, o trítio permite fazer uma ponte entre as disciplinas no que diz respeito à escala de tempo. A utilização de isótopos estáveis possui uma limitação e pode "esconder" parcelas do fluxo que possuem longos tempos de residência, levando a uma conclusão equivocada do comportamento geral do fluxo subterrâneo em uma bacia hidrográfica. Portanto, os autores encorajam a comunidade científica a continuarem os estudos utilizando o trítio para a compreensão dos fluxos em bacias hidrográficas, o que vem ganhando mais precisão devido à estabilização dos teores nas precipitações mundiais.

O trabalho de CARTWRIGHT et al. (2018) realizou uma avaliação dos controles e incertezas no tempo médio de residência em duas cabeceiras de bacias hidrográficas em diferentes condições sazonais de fluxo. Os autores buscaram correlacionar atributos físicos das bacias como, densidade de drenagem, área de contribuição, uso do solo, declividade e íons maiores, com o tempo médio de residência baseado em dados de trítio. As concentrações do trítio nas águas superficiais variaram entre 1,26 e 1,99 UT, menores do que os valores observados nas precipitações, de 3,0 UT. No geral, foi verificado que não houve boas correlações entre o tempo médio de residência e atributos físicos das bacias estudadas. No entanto, algumas correlações puderam ser observadas em determinadas sub-bacias, porém de maneira isola- 
da. O coeficiente de escoamento superficial mostrou uma boa resposta geral para as cabeceiras de bacias estudadas, mostrando ser um indicador robusto para se estimar o tempo médio de residência de bacias hidrográficas. Os autores sugerem que o tempo médio de residência é provavelmente controlado por uma interação entre alguns dos atributos físicos das bacias como declividade, densidade de drenagem, propriedades hidráulicas de solos, regolitos e aquíferos e taxas de evapotranspiração. No entanto, ainda não é clara a relação desses parâmetros com o tempo médio de residência em macroescala em bacias hidrográficas.

Aprimorando o trabalho descrito anteriormente, CARTWRIGHT et al. (2020) expandiram para quatro o número de cabeceiras de bacias hidrográficas estudadas na região sudeste da Austrália, utilizando a mesma metodologia, resultando em 29 sub-bacias. Os autores explicitam a necessidade de incrementar os estudos relacionando o tempo médio de residência e as características das bacias, de modo a revelar as relações que controlam o sistema. As concentrações de trítio nas águas superficiais variaram entre 0,20 e 2,19 UT, tendo sido estimados tempos médios de trânsito variando de alguns anos a superiores a 200 anos, utilizando os modelos exponencial e exponencial-pistão. Embora não tenham sido identificadas fortes correlações com a maioria das características estudadas para as bacias, o coeficiente de drenagem superficial e o teor de sódio mostraram correlações moderadas a fortes com o tempo médio de trânsito, dependendo da bacia. Foram discutidas relações com resultados encontrados em outros trabalhos realizados em cabeceiras de bacias na Nova Zelândia, onde o contexto fisiográfico difere acentuadamente. Os autores concluem que uma parcela significativa de águas com longo tempo de residência pode ser encontrada em cabeceiras de bacias, indicando um armazenamento considerável, com papel fundamental na geração do fluxo superficial. Assim, há necessidade do melhor entendimento de parâmetros hidráulicos de camadas intemperizadas e aquíferos fraturados que estão fortemente associados nesse contexto.

\section{PERSPECTIVAS FUTURAS}

Como já observado na Introdução desse artigo, o trítio lançado na atmosfera pelos testes nucleares praticamente já se extinguiu. $\mathrm{O}$ estoque nas águas subterrâneas apresenta níveis de radioatividade ainda menores. Isso coloca um sério obstáculo para a sua utilização na datação de águas modernas; águas com mais de 100 anos ( $\sim 9$ meias vidas do ${ }^{3} \mathrm{H}$ ) são atualmente datadas com considerável imprecisão. Salienta-se que os fabricantes de espectrômetros de cintilação líquida alcançaram significativos progressos que possibilitam atualmente medir atividades da ordem de poucos décimos de UT e que isso viabilizará a pesquisa de um largo espectro de processos ambientais ou de outros campos da ciência, mas a datação das águas modernas pelo trítio inevitavelmente ficará limitada.

Existem outras metodologias para a datação baseadas em traçadores. A mais conhecida é a que usa os clorofluorcarbonos, CFCs, empregados como traçadores em hidrologia desde os anos 70 do século passado (IAEA 2006, LEIBUNDGUT et al. 2009). As fontes dos CFCs na atmosfera são fluidos de refrigeração que começaram a ser utilizados na década de 1930. São compostos orgânicos halogenados gasosos, sintéticos, que ao escaparem para o meio ambiente, podem se dissolver na água, seguindo a lei de Henry, e nela se acumular com o tempo. Ou seja, ao contrário do ${ }^{3} \mathrm{H}$, a curva dos CFCs na água é ascendente e é ela que informa em que tempo a água penetrou no solo (Figura 13). Contudo, o uso de CFCs acarreta vários outros problemas. As moléculas destes traçadores são muito diferentes da água, suas solubilidades na água variam fortemente com a temperatura. Portanto é preciso dispor de registros precisos de séries temporais de CFCs na atmosfera, sem contar que é possível ocorrer descargas descontroladas destes gases. A precisão do método só permite datar águas muito jovens $(\leq 50$ anos). Para piorar, os CFCs contribuem para a redução da camada de ozônio e têm sido banidos em vários países. Como bem observaram CLARK \& FRITZ (1997), tal qual o trítio, foi mais um contaminante da atmosfera para o qual os hidrologistas encontraram uma serventia - mas não substituirá $\mathrm{o}^{3} \mathrm{H}$.

Quais seriam os outros candidatos? O gás hexafluoreto de enxofre $\left(\mathrm{SF}_{6}\right)$ foi cogitado por ser extremamente inerte, mas sua dissolução na água sofre a influência da temperatura e da pressão, além de haver suspeitas sobre sua ocorrência em rochas ígneas e em fluidos vulcânicos (LEIBUNDGUT et al. 2009). Uma grande esperança está depositada em isótopos dos gases nobres, todos eles obviamente inertes e disponíveis na natureza. $\mathrm{O}$ isótopo estável ${ }^{3} \mathrm{He}$ inclusive já 


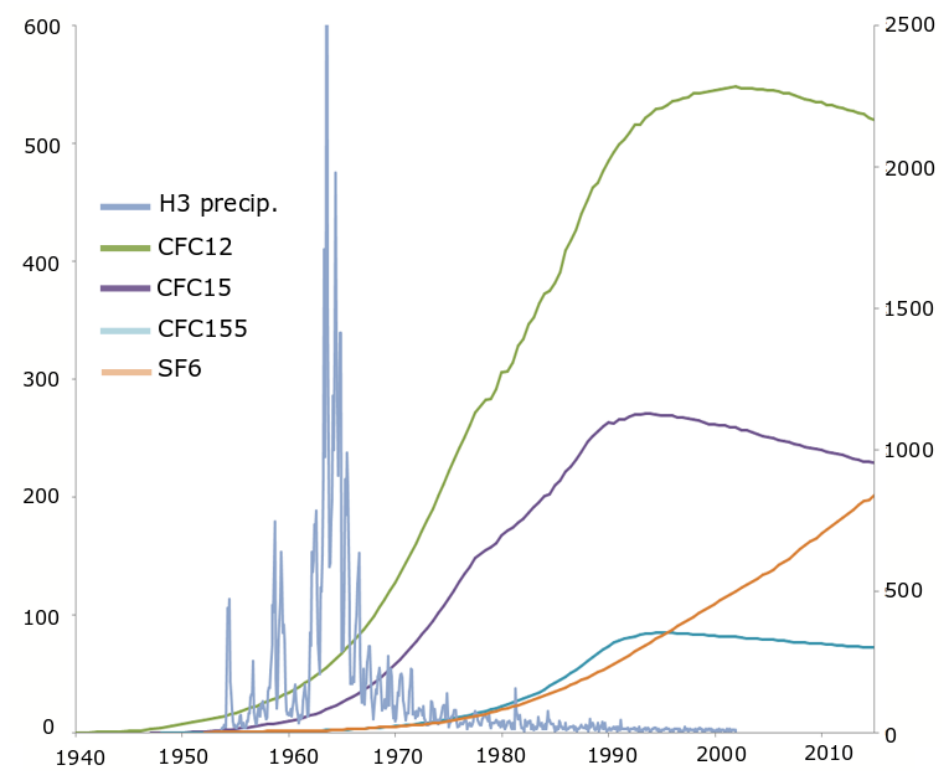

FIGURA 13 - Evolução das concentrações de trítio (H3 precip.), clorofluorcarbonos (CFC12, CFC15, CFC155) e hexafluoreto de enxofre (SF6) na atmosfera terrestre. Fonte: USGS - https://water.usgs.gov/lab/software/ air_curve/index.html.

está sendo usado na sequência do desaparecimento do trítio, visto ser um produto do decaimento do mesmo (Figura 13). A ideia é usar a razão ${ }^{3} \mathrm{H} /{ }^{3} \mathrm{He}$ nas águas: o tratamento das equações de decaimento do ${ }^{3} \mathrm{H}$ e de crescimento do ${ }^{3} \mathrm{He}$, leva à seguinte expressão para a idade da água:

$$
t=\frac{1}{\lambda} \ln \left(\frac{{ }^{3} \mathrm{H}}{{ }^{3} \mathrm{He}+1}\right)
$$

onde $\lambda=\ln 2 / t_{1 / 2}$ e $t_{1 / 2}=12,32 a$ é a meia vida do trítio. $\mathrm{O}$ método tem relevantes vantagens: não requer o sempre desconhecido valor inicial do radionuclídeo, tem alta resolução e poderá ser empregado por um longo tempo. Mas no presente estágio ainda enfrenta árduos desafios: o custo e a complexidade dos métodos e equipamentos analíticos que confinam sua prática a poucos laboratórios, bem como as dificuldades para evitar perdas ou contaminação do hélio tritiogênico por hélio de outras fontes (KAZEMI et al. 2006, CLARK 2015).

Outro isótopo de gás nobre despontando é o ${ }^{85} \mathrm{Kr}$, cuja meia-vida é 10,76 anos e é formado na atmosfera em pequenas quantidades pela ativação do mais abundante (57\%) isótopo estável do criptônio: ${ }^{84} \mathrm{Kr}+n \rightarrow{ }^{85} \mathrm{Kr}+\gamma$, ou mais simplesmente ${ }^{84} \mathrm{Kr}(n, \gamma){ }^{85} \mathrm{Kr}$. O radionuclídeo, também produzido na fissão do urânio e do plutônio, é liberado para a atmosfera por ocasião do reprocessamento dos combustíveis nucleares usados, resultando na liberação de atividades significativas do ${ }^{85} \mathrm{Kr}$ para a atmosfera, onde sua concentração tem elevado continuamente. Destarte apenas águas subterrâneas juvenis, precipitadas após a década de 1960, contêm ${ }^{85} \mathrm{Kr}$. Por outro lado, dada a contínua elevação da atividade, é possível datar águas extremamente jovens, na faixa de 1 a 5 anos. Mas a atividade deste radioisótopo é $\sim 30 \%$ mais baixa no hemisfério sul, o que exige a concentração das amostras de água para se alcançar o grau de exatidão requerido para a datação. Sendo a mais abundantemente emitida pelo ${ }^{85} \mathrm{Kr}$, a radiação $\beta$ (680 kev) tem sua contagem feita por cintilação líquida, igual ao trítio. Há também um outro radioisótopo do criptônio no meio ambiente, o ${ }^{81} \mathrm{Kr}$, cuja meia vida de 229.000 anos capacita-o a datar águas muito antigas (40 - 1.300 ka), não mensuráveis pelo ${ }^{14} \mathrm{C}$.

O radionuclídeo ${ }^{85} \mathrm{Kr}$ é produzido pelos efeitos dos raios cósmicos na atmosfera via reações ${ }^{80} \mathrm{Kr}(n, \gamma){ }^{81} \mathrm{Kr}$ e ${ }^{82} \mathrm{Kr}(\gamma, n){ }^{81} \mathrm{Kr}$ e seu decaimento dá-se via captura eletrônica. A medição também requer pré-concentração das amostras; em função das ultrabaixas atividades no ambiente é demandada a evaporação de grandes volumes em campo. Essas concentrações do ${ }^{81} \mathrm{Kr}\left(<10^{-12}\right)$ podem ser medidas pela metodologia ATTA (Atom Trap Trace Analysis) (MATSUMOTO et al. 2020), um método 
extremamente sensível de fluorescência induzida por laser, mas ainda em processo de desenvolvimento. Sendo insignificantes as contribuições tecnogênicas para a geração do ${ }^{81} \mathrm{Kr}$, o traçador oferece a vantagem de que os parâmetros de entrada nos sistemas são constantes. Porém, um enorme obstáculo atualmente colocado para a utilização da metodologia ATTA é que estes equipamentos são de altíssimo custo e disponíveis em apenas poucos países no mundo (LIGHT et al. 2019), e ainda se encontram em processo de contínua evolução (JIANG et al. 2017).

O radioisótopo ${ }^{39} \mathrm{Ar}$ é uma promessa com maiores expectativas pois, devido à sua meia vida de 269 anos, poderá preencher um espaço entre as técnicas de datação. A vida média do trítio $\left(\mathrm{t}_{1 / 2}=\right.$ 12,3 a) é insuficiente para medir idades de água com mais de $\sim 120 \mathrm{a}$, enquanto o ${ }^{14} \mathrm{C}\left(\mathrm{t}_{1 / 2}=5730 \mathrm{a}\right)$ é muito longevo para medir águas com idades inferiores a 700 a. Numa água infiltrada a menos de 700 anos a atividade do ${ }^{14} \mathrm{C}$ não terá decaído o suficiente para alterar a atividade com que ela entrou no solo. Observa-se então um hiato de quase 600 anos, impossibilitado de ser datado pelos traçadores naturais e nem mesmo pelos CFC's ou pelo par ${ }^{3} \mathrm{H} /{ }^{3} \mathrm{He}$, sendo que muitas águas subterrâneas podem ter idades dessa magnitude.

$\mathrm{O}{ }^{39} \mathrm{Ar}$, como os demais radioisótopos de gases nobres, é gerado na atmosfera pela ação dos raios cósmicos, sendo que a contribuição das poucas fontes tecnogênicas é desprezível - uma delas é a irradiação de rochas dentro de reatores nucleares por nêutrons rápidos para produzir $0^{39} \mathrm{Ar}$ necessário para o método ${ }^{40} \mathrm{Ar} /{ }^{39} \mathrm{Ar}$ de datação de rochas. A formação do radionuclídeo na natureza se dá a partir da mesma reação: ${ }^{39} \mathrm{~K}(n, p){ }^{39} \mathrm{Ar}$. Remover um próton de um núcleo atômico leve requer considerável quantidade de energia, a qual é fornecida pelos nêutrons energéticos induzidos pelas radiações cósmicas e pelos nêutrons rápidos recém-formados na fissão do ${ }^{235} \mathrm{U}$. Do balanço entre a formação e o decaimento do ${ }^{39} \mathrm{Ar}$ resulta uma quantidade estacionária do radionuclídeo na atmosfera da ordem de $1,67 \times 10^{-2} \mathrm{~Bq} / \mathrm{m}^{3}$, ou 1 átomo de ${ }^{39} \mathrm{Ar}$ para cada átomo de argônio, cuja abundância na atmosfera é $0,93 \%$, numa base volumétrica. Constata-se mais uma vez o desafio de se trabalhar com quantidades muito diminutas; estima-se que amostras de água da ordem de até $2.000 \mathrm{~L}$ tenham que ser degasadas no campo (cuidadosamente evitando-se a contaminação por ar moderno), a fim de se alcançar uma concentração de atividade adequada para as medidas espectrométricas. Atualmente os equipamentos usados para a análise do ${ }^{39} \mathrm{Ar}$ têm sido os baseados na técnica ATTA, que admite volumes menores (IAEA 2013, JIANG et al. 2017, EBSER el al. 2018, FENG et al. 2019). Em raros casos a interpretação dos resultados obtidos com $\mathrm{o}{ }^{39} \mathrm{Ar}$ pode ser dificultada em função da produção do radionuclídeo na própria rocha via reação ${ }^{39} \mathrm{~K}(n, p)^{39} \mathrm{Ar}$.

Verifica-se um grande avanço da tecnologia de espectrometria de massas nas medidas de nuclídeos estáveis e inclusive alguns radioativos de meia-vida muito longa nas duas ou três últimas décadas. Nota-se igualmente um interesse crescente pelo emprego dos gases nobres em hidrologia, fortemente suscitado pelo esgotamento do trítio remanescente dos testes nucleares nos anos 1960. Os gases nobres não são como a água tritiada, um traçador quase-perfeito da água, mas estão muito mais próximos deste desempenho do que os outros materiais que têm sido utilizados, principalmente pela sua estabilidade e passividade química, além do fato de serem naturais e apresentar-se em formas estáveis (traçador do comportamento da água) ou radioativa (datação), com cinética de decaimento não afetada pelas condições do ambiente. Não obstante, no presente estágio ainda foram relativamente pouco utilizados, na maioria das vezes em trabalhos de pesquisa especializados, simultaneamente com outros traçadores, frequentemente testando o seu próprio desempenho.

De longe, os maiores responsáveis por essa paucidade foram a escassez de equipamentos especializados, os custos e até os esforços analíticos. Contudo, verifica-se que há uma tendência contraposta a essa situação. Talvez ainda vagarosa, mas irreversivelmente, a metodologia da espectrometria de massa vai se expandindo, não somente nos números de usuários, mas também na diversificação dos próprios fundamentos. A introdução da espectrometria de massa por absorção de laser irrompeu em um curto espaço de tempo em laboratórios de análise química e em departamentos de hidrologia em todo o globo. A tendência é que estas técnicas analíticas, especificamente a espectrometria de cintilação líquida (LSC) e as espectrometrias de massas (em especial a AMS) passem a ocupar cada vez mais o espaço que hoje é servido pelos métodos radiométricos, posto que estes contam os decaimentos (de alguns nuclídeos numa amostra), enquanto na espectrometria de massa são contados todo os nuclídeos dessa mesma amostra. Por outro lado, o avanço da espectrometria de massas com acelerador de íons tem feito progressos notáveis, reduzindo a escala física dos equipamentos, 
bem como os custos de implantação e operação. Embora estes continuem em níveis impeditivos de uma ampla e frequente utilização pelos hidrologistas, o ritmo do desenvolvimento autoriza prever que se tornem ferramentas de uso assíduo até o final da presente década.

A análise com o método ATTA, também com base no laser, é a promessa mais recente para a expansão do uso de radioisótopos de gases nobres, dotados de excelentes características como traçadores em hidrologia, mas ainda pouquíssimo utilizado por conta de suas insignificantes concentrações no meio ambiente. Devido à excepcional sensibilidade da ATTA, é possível que num futuro não muito distante se consiga medir o trítio em níveis abaixo de 1 mUT (SUCKOW 2020).

Um prognóstico de rápido desenvolvimento destas sofisticadas técnicas e de acesso ao seu uso é reforçado por uma pressão que vem de várias outras áreas, além da hidrologia: na oceanografia, com seu interesse sobre a circulação oceânica e os seus tempos de trânsito; na geologia, em estudos sobre a circulação profunda de fluidos na crosta terrestre e no manto; projetos de sequestro de $\mathrm{CO}_{2}$ poderiam ser aprimorados com a previsão do comportamento do gás no subsolo (LU et al. 2014). As Geociências, de uma maneira geral, se beneficiariam da metodologia ATTA para as medições de rotina e para suas pesquisas.

\section{AGRADECIMENTOS}

Aos relatores da revista pelas sugestões apresentadas.

\section{REFERÊNCIAS BIBLIOGRÁFICAS}

AFFOLTER, S.; STEINMANN, P.; AEMISEGGER，F.; PURTSCHERT, R.; LEUENBERGER, M. 2020. Origin and percolation times of Milandre Cave drip water determined by tritium time series and beryllium-7 data from Switzerland. Journal of Environmental Radioactivity, 222: 106346. https://doi.org/10.1016/j. jenvrad.2020.106346.

ALBARÈDE, F. 2009. Geoquímica - Uma Introdução. Oficina de Textos, São Paulo, $400 \mathrm{p}$.

AMIN, I.E.; CAMPANA, M.E. 1996. A general lumped parameter model for the interpretation of tracer data and transit time calculation in hydrologic systems. Journal of Hydrology, 179(1): 1-21. https://doi.org/10.1016/00221694(95)02880-3

BEDMAR A.P.; ARAGUÁS; L.A. 2002. Detection and prevention of leaks from dams, A.A. Balkema Publishers, Lisse, 419 p.

BEDMAR, A.P.; DA SILVA, A.B. 1980. Utilização de isótopos ambientais na pesquisa de recursos hídricos subterrâneos no karst da região do Jaíba, norte de Minas Gerais. In: ABAS, CONGRESSO BRASILEIRO DE ÁGUAS SUBTERRÂNEAS, 1, Recife, Anais, p. 147-168. https://aguassubterraneas. abas.org/asubterraneas/article/view/23703.

CANADIAN NUCLEAR SAFETY COMMISSION. 2009. Tritium in Drinking Water. Disponível em http://nuclearsafety. gc.ca/eng/resources/health/tritium/tritiumin-drinking-water.cfm. Acessado em 28 set. 2020.

CARTWRIGHT, I.; IRVINE, D.; BURTON, C.; MORGENSTERN, U. 2018. Assessing the controls and uncertainties on mean transit times in contrasting headwater catchments. Journal of Hydrology, 557: 16-29. https:// doi.org/10.1016/j.jhydrol.2017.12.007.

CARTWRIGHT, I.; MORGENSTERN, U.; HOWCROFT, W.; HOFMANN, H.; ARMIT, R.; STEWART, M.; BURTON, C.; IRVINE, D. 2020. The variation and controls of mean transit times in Australian headwater catchments. Hydrological Processes, 34(21): 4034-4048. https://doi.org/10.1002/ hyp. 13862 .

CARVALHO, J.B. 2012. Avaliação isotópica e hidroquímica na porção noroeste do aquífero Cauê, Quadrilátero Ferrífero, Brasil. Centro de Desenvolvimento da Tecnologia Nuclear, Belo Horizonte, Dissertação de Mestrado, $124 \mathrm{p}$.

CELLE-JEANTON, H., GOURCY, L., AGGARWAL, P.K. 2002. Reconstruction of tritium time series in precipitation. In: IAEA, INTERNATIONAL CONFERENCE ON "STUDYOFENVIRONMENTALCHANGE USING ISOTOPE TECHNIQUES", Vienna, Proceedings, 430-432. 
CLARK, I. 2015. Groundwater Geochemistry and Isotopes, CRC Press, Bocca Raton, FL., $456 \mathrm{p}$.

CLARK, I.; FRITZ, P. 1997 Environmental Isotopes in Hydrogeology. CRC Press, Bocca Raton, FL., 327 p.

CNEN - COMISSÃO NACIONAL DE ENERGIA NUCLEAR. 2014. Norma CNEN NN 3.01 Diretrizes Básicas de Proteção Radiológica Disponível em http://appasp.cnen.gov. $\mathrm{br} /$ seguranca/normas/pdf/Nrm301.pdf. Acessado em 28 set. 2020.

CORCHO ALVARADO, J.A.; BARBECOT, F.; PURTSCHERT, R. 2009. Ambient vertical flow in long-screen wells: a case study in the Fontainebleau Sands Aquifer (France). Hydrogeology Journal, 17(2): 425-431. https://doi.org/10.1007/s10040-008-0383-1

COTA, S.; PEIXOTO, C.M.; BARRETO, A.A.; GASTMANS, D.; SANTOS, V.; TERZER, S.; ARAGUÁS-ARAGUÁS, L. 2013. GNIP stations in Brazil: Importance, past and current developments. In: ABAS, CONGRESSO INTERNACIONAL DE MEIO AMBIENTE SUBTERRÂNEO, 3, São Paulo, Anais, 4 p.

CRISS, R.E. 1999. Principles of Stable Isotope Distribution. Oxford University Press, New York, $254 \mathrm{p}$.

DINÇER, T.; DAVIS, G.H. 1984. Application of environmental isotope tracers to modeling in hydrology. Journal of Hydrology, 68(1): 95-113. https://doi.org/10.1016/00221694(84)90206-3

DONEY, S.C.; GLOVER, D.M.; JENKINS, W.J. 1992. A model function of the global bomb tritium distribution in precipitation, 1960 1986. Journal of Geophysical Research Oceans, 97(C4): 5481-5492. https://doi. org/10.1029/92JC00015

EBSER, S.; KERSTING, A.; STÓVEN, T.; FENG, Z.; RINGENA, R.; SCHMIDT, M.; TNAHUA, T.; AESCHBACH, W.; OBERTHALER, M.K. 2018. ${ }^{39} \mathrm{Ar}$ Dating with Small Samples Provides New Key Constraints on Ocean Ventilation. Nature Communications, 9(1): 5046. https://doi. org/10.1038/s41467-018-07465-7
FAURE, G., MESSING, T.M. 2005. Isotopes - Principles and Appplications. Wiley, Hoboken, NJ, $3^{\text {rd }}$. ed., 897 p.

FENG, Z.; BOHLEBER, P.; EBSER, S.; RINGENA, L.; SCHMIDT, M.; KERSTING, A.; HOPKINS, P.; HOFFMANN. A.; FISCHER, A., AESCHBACH, W.; OBERTHALER, M.K. 2019. Dating Glacier Ice of the Last Millenium by Quantum Technology. PNAS, 116(18): 8781-8786. https://doi.org/10.1073/pnas.1816468116

FERRONSKY, V.I.; POLYAKOV, V.A. 2012. Isotopes of the Earth's Hydrosphere. Springer, Dordrecht, $628 \mathrm{p}$.

FRANZINI, A.S.; KIRCHHEIM, R.E.; NOGUEIRA, G.S.; NIEMAYER, A.F.; OLIVEIRA, F.R.; GASTMANS, D.; MARTINS, V.; COTA, S.D.; TERZERWASSMUTH, S.; ORTEGA, L. 2019. The new GNIP network in Brazil: an example of sound institutional arrangements. In: INTERNATIONAL SYMPOSIUM ON ISOTOPE HYDROLOGY: Advancing the Understanding of Water Cycle Processes, Vienna.

GAT, J. 2010. Isotope hydrology: a study of the watercycle, Imperial College Press, London, 189 p.

GEYH, M. 2000. Series on Environmental Isotopes in the Hydrologic Cycle-Principles and Applications, Vol. IV, Groundwater Saturated and Unsaturated Zone. United Nations Educational, Scientific and Cultural Organization and International Atomic Energy Agency, Paris/Vienna, 205 p.

GRABCZAK, J.; RÓŻAŃSKI, K.; MALOSZEWSKI, P.; ZUBER, A. 1984. Estimation of the tritium input function with the aid of stable isotopes, Catena, 11(2-3): 105-114. https:// doi.org/10.1016/0341-8162(84)90001-8

IAEA - INTERNATIONAL ATOMIC ENERGY AGENCY. 2006. Use of chlorofluorocarbons in hydrology. A guidebook. IAEA, Vienna, $277 \mathrm{p}$.

IAEA - INTERNATIONAL ATOMIC ENERGY AGENCY. 2012. Application of Radiotracer Techniques for Interwell Studies. IAEA 
Radiation Technology Series No. 3, IAEA, Vienna, 248 p.

IAEA - INTERNATIONAL ATOMIC ENERGY AGENCY. 2013. Isotope Methods for Dating Old Groundwaters. IAEA, Vienna, 357 p.

IAEA - INTERNATIONAL ATOMIC ENERGY AGENCY. 2014. Radiation Protection and Safety of Radiation Sources: International Basic Safety Standards - IAEA Safety Standards Series No. GSR Part 3. IAEA, Vienna, $436 \mathrm{p}$.

JIANG, W.; YANG, G.-M.; GU, J.-Q.; HU, S.-M.; LU, Z.-T. 2017. Radiokrypton dating with Atom Trap Trace Analysis. Procedia Earth and Planetary Sciences, 17: 41-44. https:// doi.org/10.1016/j.proeps.2016.12.020

JURGENS， B.; BÖHLKE， J.; EBERTS， S. 2012. TracerLPM (Version 1): An Excel $\mathbb{R}$ Workbook for Interpreting Groundwater Age Distributions from Environmental Tracer Data. U.S. Department of the Interior, USGS.

KASHIWAYA, K.; MUTO, Y.; KUBO, T.; IKAWA, R.; NAKAYA, S.; KOIKE, K.; MARUI, A. 2017. Spatial variations of tritium concentrations in groundwater collected in the southern coastal region of Fukushima, Japan, after the nuclear accident. Scientific Reports, 7: 12578. https://doi.org/10.1038/ s41598-017-12840-3.

KAZEMI, G.A.; LEHR, J.H.; PERROQUET; P. 2006. Groundwater age. Wiley-Interscience, Hoboken, NJ, 346 p.

KENDALL， C.; CALDWELL， E.A. 1998. Fundamental of Isotope Geochemistry. In: C. Kendall \& J.J. McDowell (ed.) Isotope Tracers in Catchment Hydrology. Elsevier, Amsterdam, p.51-86.

KINZELBACH， W.; AESCHBACH， W.; ALBERICH, C.; GONI, I.; BEYERLE, U.; BRUNNER, P.; CHIANG, W.-H.; RUEEDI, J.; ZOELLMANN, K. 2002. A Survey of Methods for Groundwater Recharge in Arid and Semi-arid regions. Nairobi, Kenya: United Nations Environment Programme. http://wedocs.unep.org/handle/20.500.11822/8195

KREFT, A.; ZUBER, A. 1978. On the physical meaning of the dispersion equation and its solutions for different initial and boundary conditions. Chemical Engineering Science, 33(11): 1471-1480. https://doi. org/10.1016/0009-2509(78)85196-3

KUMAR, B.; HAN, L.F.; WASSENAAR, L.I.; KLAUS,P.M.;KAINZ,G.G.;HILLEGONDS, D.; AHMAD, M.; BELACHEW, D.L.; ARAGUÁS, L.; AGGARWAL, P. 2016. A compact tritium enrichment unit for large sample volumes with automated re-filling and higher enrichment factor. Applied Radiation and Isopopes, 118: 80-86. https:// doi.org/10.1016/j.apradiso.2016.07.018

LEIBUNDGUT, C.; MALOSZEWSKI, P.; KÜLLS, C. 2009. Tracers in Hydrology. John Wiley \& Sons, Ltd.

LIGHT, P.S.; GLOVER, R.D.; DAKKA, M.A.; TSIMINIS, G.; PALMER, A.J. CHETTY, D.; LITVINYUK, I.; SANG, R.T.; LUITEN. A.N. 2019. Towards an Australian AtomTrap Trace Analysis (ATTA) facility. In: AOS Australian Conference on Optical Fibre Technology (ACOFT) and Australian Conference on Optics, Lasers, and Spectroscopy (ACOLS), Melbourne, Proceedings, Volume 11200.

LINDSEY, B.D.; JURGENS, B.C.; BELITZ, K. 2019. Tritium as an indicator of modern, mixed, and premodern groundwater age. U.S. Geological Survey Scientific Investigations Report 2019-5090, 18 p. https://doi. org/10.3133/sir20195090.

LOWENTHAL, G.C.; AIREY. P.L. 2001. Practical Applications of Radioactivity and Nuclear Radiations. Cambridge University Press, Cambridge, UK, 366 p.

LU, Z.-T.; SCHLOSSER, P., SMETHIE JR. W.M.; STURCHIO, N.C.; FISCHER, T.P.; KENNEDY, B.M.; PUTSCHERT, R., SEVERINGHAUS, J.P.; SOLOMON, D.K.; TAUHUA, T.; YOKOSHI, R. 2014. Tracer Applications of Noble Gas Radionuclides in the Geosciences. Earth Science Reviews, 138: 196-214. https://doi.org/10.1016/j. earscirev.2013.09.002

MALOSZEWSKI, P.; ZUBER, A. 1982. Determining the turnover time of groundwater systems with the aid of environmental tracers. 
Journal of Hydrology, 57(3): 207-231. https:// doi.org/10.1016/0022-1694(82)90147-0

MALOSZEWSKI, P.; ZUBER, A. 1996. Manual on Mathematical Models in Isotope Hydrology. IAEA-TECDOC-910, Vienna, Austria, IAEA, v. 1, p. 9-58.

MALOSZEWSKI, P.; STICHLER, W.; ZUBER A.; RANK D. 2002. Identifying the flow systems in a karstic-fissured-porous aquifer, the Schneealpe, Austria, by modelling of environmental ${ }^{18} \mathrm{O}$ and ${ }^{3} \mathrm{H}$ isotopes. Journal of Hydrology, 256(1): 48-59. https://doi. org/10.1016/S0022-1694(01)00526-1

MASARIK, J. 2010. Origin and distribution of radionuclides in the continental environment, In: K. Froehlich, (ed.) Environmental Radionuclides. Tracers and Timers of Terrestrial Processes. Amsterdam, Elsevier, p. 1-25.

MATSUMOTO, T.; ZOUARI, K.; TRABELSI, R., HILLEGONDS, D.; JIANG, W.; TIANLU, Z., MUELLER, P.; ZAPPALA, J.C.; ARAGUÁS ARAGUÁS, L.J.; ROMEO, N.; AGOUN, A. 2020. Krypton-81 dating of the deep Continental Intercalaire aquifer with implications for chlorine-36 dating. Earth and Planetary Science Letters, 535, 1 April 2020: 116120 https://doi.org/10.1016/j. epsl.2020.116120

MAZOR, E. 2003. Chemical and Isotopic Groundwater Hydrology. CRC Press, Boca Raton FL, 472 p.

MINARDI, P.S.P; VELÁSQUEZ, L.N.M.; BOMTEMPO, V.L.; COTA, S.D.S.; RODRIGUES, P.C.H. 2008. Técnicas isotópicas aplicadas em estudos hidrogeológicos no município de Araguari, MG.In:ABAS, CONGRESSOBRASILEIRO DE ÁGUAS SUBTERRÂNEAS, 15, Natal, Anais, p. 1-11.

MOOK, W.G. 2000. Series on Environmental Isotopes in the Hydrologic Cycle-Principles and Applications, Vol. I, Introduction: Theory, Methods, Review. United Nations Educational, Scientific and Cultural Organization and International Atomic Energy Agency, Paris/Vienna, 295 p.
MORGENSTERN, U.; STEWART, M.K.; STENGER, R. 2010. Dating of streamwater using tritium in a post nuclear bomb pulse world: continuous variation of mean transit time with streamflow, Hydrology and Earth System Sciences, 14: 2289-2301. https://doi. org/10.5194/hess-14-2289-2010.

MOSQUERA, G. M.; SEGURA, C.; VACHÉ, K.B.; WINDHORST, D.; BREUER, L.; CRESPO, P. 2016. Insights into the water mean transit time in a high-elevation tropical ecosystem. Hydrology and Earth System Sciences, 20(7): 2987-3004. https://doi.org/10.5194/hess-202987-2016.

MOURÃO, M.A.A. 2007. Caracterização hidrogeológica do aquífero Cauê, Quadrilátero Ferrifero, $M G$. Universidade Federal de Minas Gerais, Belo Horizonte, Tese de Doutorado, 321 p. http://hdl.handle. net/1843/ENGD-7AJNZE

SHARP, Z. 2007. Principles of stable isotope geochemistry. Pearson Prentice Hall, Upper Saddle River, NJ, 344 p.

SILVA, A.; COTA, S. 2021. Groundwater age dating using single and time-series data of environmental tritium in the Moeda Synclyne, Quadrilátero Ferrífero, Minas Gerais, Brazil. Journal of South American Earth Sciences, 107: 103009. https://doi. org/10.1016/j.jsames.2020.103009.

SOLDER, J.E.; STOLP, B.J.; HEILWEIL, V.M.; SUSONG, D.D. 2016. Characterization of mean transit time at large springs in the Upper Colorado River Basin, USA: a tool for assessing groundwater discharge vulnerability. Hydrogeology Journal, 24(8): 2017-2033. https://doi.org/10.1007/s10040016-1440-9.

STEWART, M.K.; MORGENSTERN, U. 2016. Importance of tritium-based transit times in hydrological systems. WIREs Water, 3: 145154. https://doi.org/10.1002/wat2.1134.

STEWART, M.K.; MORGENSTERN, U.; MCDONNELL, J.J. 2010. Truncation of stream residence time: how the use of stable isotopes has skewed our concept of streamwater age and origin. Hydroogical 
Processes, 24: 1646-1659. https://doi. org/10.1002/hyp.7576.

SUCKOW, A. 2010. Analysis of radionuclides, In: K. Froehlich (ed.) Environmental Radionuclides. Tracers and Timers of Terrestrial Processes. Amsterdam, Elsevier, p. 363-406.

UNIVERSITY OF WATERLOO. Earth Sciences Museum. 2021. https://uwaterloo.ca/earthsciences-museum/resources/detailedrocks-and-minerals-articles/tritium, Acessado em 13/02/2021.

UREY, H.C. 1947. The thermodynamic properties of isotopic substances. Journal of Chemical Society, 31: 611-614.

WHITE, W.M. 2015. Isotope Geochemistry. Wiley Blackwell, Chichester, 478 p.
ZHAI, Y.; WANG, J.; GUO, H.; CAO, Y.; TENG, Y. 2013. Reconstruction and Optimization of Tritium Time Series in Precipitation of Beijing, China. Radiocarbon, 55(1): 67-79. https://doi.org/10.2458/azu_js_ rc.v55i1.16043

ZUBER, A.; CIEZKOWSKI, W. 1999. Use of Isotopes for Analyses of Flow and Transport Dynamics in Groundwater Systems. Coordinated Research Project, Vienna, Austria, IAEA, v. 1, p. 1-22.

ZUBER, A.; MALOSZWESKI, P. 2001. Environmental isotopes in the hydrological. In: Y. Yourtsever (Ed.) Modelling. Vienna, Austria, UNESCO/IAEA, vol. 6, p. 497515.

Endereço dos autores:

Aurélio Fernando Paiva Silva - Rua José Cordeiro, n 67, CEP 30642-080, Belo Horizonte, MG, Brasil. E-mail: aurelio.ferdinand@gmail.com

Stela Dalva Santos Cota e Rubens Martins Moreira - Centro de Desenvolvimento da Tecnologia Nuclear - CDTN/CNEN, Av. Presidente Antônio Carlos, n 6.627, CEP 31270-901, Belo Horizonte, MG, Brasil. E-mails:sdsc@cdtn.br, rubens@cdtn.br

Artigo submetido em 12 de novembro de 2020, aceito em 1 de março de 2021. 